\title{
Medicago truncatula adjusts root proliferation, nodule formation, and partner choice in response to local $\mathrm{N}$ heterogeneity
}

\author{
Xuechun Zhang, Lucian Wang, Judith Li, Rebecca T. Batstone, \\ Megan E. Frederickson
}

Version Post-Print $\backslash$ Accepted Manuscript

Citation Zhang, X., Wang, L., Li, J. et al. Medicago truncatula adjusts root proliferation, (published nodule formation, and partner choice in response to local $\mathrm{N}$ heterogeneity. Plant Soil version) 450, 417-428 (2020). https://doi.org/10.1007/s11104-020-04433-3

\footnotetext{
Publisher 1. Archived content may only be used for academic research. Any content downloaded for text Terms of Use based experiments should be destroyed when the experiment is complete.

2. Archived content may not be used for purposes that are intended for or directed towards commercial advantage or monetary compensation by means of sale, resale, licence, loan, transfer or any other form of commercial exploitation ("Commercial Purposes").

3. Archived content may not be published verbatim in whole or in part, whether or not this is done for Commercial Purposes, either in print or online.

4. This restriction does not apply to reproducing normal quotations with an appropriate citation. In the case of text-mining, individual words, concepts and quotes up to 100 words per matching sentence may be used, whereas longer paragraphs of text and images cannot (without specific permission from Springer Nature).

5. All use must be fully attributed. Attribution must take the form of a link - using the article DOI - to the published article on the journal's website.

6. All use must ensure that the authors' moral right to the integrity of their work is not compromised.

7. Where content in the document is identified as belonging to a third party, it is the obligation of the user to ensure that any use complies with copyright policies of the owner.

8. Any use of Springer Nature content is at your own risk and Springer Nature accepts no liability arising from such use.
}

How to cite TSpace items

Always cite the published version, so the author(s) will receive recognition through services that track citation counts, e.g. Scopus. If you need to cite the page number of the author manuscript from TSpace because you cannot access the published version, then cite the TSpace version in addition to the published version using the permanent URI (handle) found on the record page.

This article was made openly accessible by $U$ of $T$ Faculty. Please tell us how this access benefits you. Your story matters. 


\section{Plant and Soil}

\section{Medicago truncatula adjusts root proliferation, nodule formation, and partner choice in response to local $\mathrm{N}$ heterogeneity

\author{
--Manuscript Draft--
}

\begin{tabular}{|c|c|c|}
\hline Manuscript Number: & \multicolumn{2}{|l|}{ PLSO-D-19-00296R3 } \\
\hline Full Title: & \multicolumn{2}{|c|}{$\begin{array}{l}\text { Medicago truncatula adjusts root proliferation, nodule formation, and partner choice in } \\
\text { response to local } \mathrm{N} \text { heterogeneity }\end{array}$} \\
\hline Article Type: & \multicolumn{2}{|l|}{ Manuscript } \\
\hline Keywords: & \multicolumn{2}{|c|}{$\begin{array}{l}\text { nitrogen deposition; legume-rhizobium symbiosis; Medicago truncatula; Ensifer } \\
\text { meliloti; nitrogen acquisition; root foraging; nodulation; partner choice; Mutualism }\end{array}$} \\
\hline Corresponding Author: & \multicolumn{2}{|l|}{$\begin{array}{l}\text { Xuechun Zhang } \\
\text { University of Toronto } \\
\text { Toronto, Ontario CANADA }\end{array}$} \\
\hline \multicolumn{3}{|l|}{$\begin{array}{l}\text { Corresponding Author Secondary } \\
\text { Information: }\end{array}$} \\
\hline Corresponding Author's Institution: & \multicolumn{2}{|l|}{ University of Toronto } \\
\hline \multicolumn{3}{|l|}{$\begin{array}{l}\text { Corresponding Author's Secondary } \\
\text { Institution: }\end{array}$} \\
\hline First Author: & \multicolumn{2}{|l|}{ Xuechun Zhang } \\
\hline \multicolumn{3}{|l|}{ First Author Secondary Information: } \\
\hline \multirow[t]{5}{*}{ Order of Authors: } & \multicolumn{2}{|l|}{ Xuechun Zhang } \\
\hline & \multicolumn{2}{|l|}{ Lucian Wang } \\
\hline & \multicolumn{2}{|l|}{ Judith $\mathrm{Li}$} \\
\hline & \multicolumn{2}{|l|}{ Rebecca Batstone } \\
\hline & \multicolumn{2}{|l|}{ Megan E. Frederickson } \\
\hline \multicolumn{3}{|c|}{ Order of Authors Secondary Information: } \\
\hline Funding Information: & $\begin{array}{l}\text { Canadian Network for Research and } \\
\text { Innovation in Machining Technology, } \\
\text { Natural Sciences and Engineering } \\
\text { Research Council of Canada } \\
\text { (RGPIN-2015-06742) }\end{array}$ & Dr. Megan E. Frederickson \\
\hline Abstract: & \multicolumn{2}{|c|}{$\begin{array}{l}\text { ABSTRACT } \\
\text { Aims } \\
\text { Increases in anthropogenic nitrogen (N) deposition are expected to lead to a higher } \\
\text { mean and lower variance of } \mathrm{N} \text { in the soil, which may disproportionately affect } \\
\text { leguminous plants that acquire } \mathrm{N} \text { both symbiotically via rhizobia and abiotically from } \\
\text { soil. Here, we investigate the effects of changing } \mathrm{N} \text {-heterogeneity at a fine spatial scale } \\
\text { on the legume-rhizobium symbiosis. } \\
\text { Methods } \\
\text { We used a split-root system to introduce local soil } \mathrm{N} \text {-heterogeneity, while maintaining } \\
\text { the same plant-level amount of } \mathrm{N} \text {. We treated root halves of five inbred lines of } \\
\text { Medicago truncatula (HapMap lines } 267,270,276,279 \text {, and } 313 \text { ) with } 50 \%-50 \% \text {, } \\
20 \%-80 \%, 10 \%-90 \% \text {, or } 2 \%-98 \% \mathrm{~N} \text { and inoculated them with two Ensifer meliloti } \\
\text { strains that differ in } \mathrm{N} \text {-fixation ability. } \\
\text { Results } \\
\text { Although shoot biomass was unaffected by N-heterogeneity, plant lines adjusted their } \\
\text { relative investments in nodulation versus root proliferation to optimize } \mathrm{N} \text {-acquisition; } \\
\text { high- } \mathrm{N} \text { root halves invested more into root proliferation, while low- } \mathrm{N} \text { root halves } \\
\text { invested more into nodule formation. We detected hidden plasticity in partner choice: } \\
\text { although all plants formed more nodules with the more effective } \mathrm{N} \text {-fixing strain, roots } \\
\text { experiencing greater } \mathrm{N}-\text {-limitation increased preference for effective } \mathrm{N} \text {-fixing rhizobia. }\end{array}$} \\
\hline
\end{tabular}


Response to Reviewers:
Furthermore, there was significant variation among lines in root proliferation and nodulation responses to $\mathrm{N}$-heterogeneity.

Conclusion

In response to $\mathrm{N}$-heterogeneity, M. truncatula exhibited phenotypic plasticity in root proliferation, nodulation, and partner choice at the half-root level. We suggest that plasticity in response to rhizosphere conditions makes legumes potentially resilient to changes in $\mathrm{N}$-heterogeneity, particularly in a time of anthropogenic $\mathrm{N}$ deposition.

\section{Response to Reviewer:}

>>The title, "Medicago truncatula adjusts root proliferation, nodule formation, and partner choice to cope with local $\mathrm{N}$ heterogeneity" still suggests belowground plasticity is a means of enhancing performance or fitness for $M$. truncatula across heterogeneous environments, which is not supported by their data. I think a title something like, "Medicago truncatula adjusts root proliferation, nodule formation, and partner choice to in response to local $\mathrm{N}$ heterogeneity" would be a more accurate description of the findings.

We agree that rewording the title would be appropriate given our last set of changes, and have updated it to "Medicago truncatula adjusts root proliferation, nodule formation, and partner choice in response to local $\mathrm{N}$ heterogeneity" (Line 1).

>>"Medicago" and "Medicago truncatula" are non consistently italicized in the text.

Thank you for bringing this to our attention. In this revision we cleaned up italicization in text (Line 378), as well as some minor formatting issues in the references (Line 499, $539,544)$.

Sincerely,

Xuechun Zhang et al. 
1 Medicago truncatula adjusts root proliferation, nodule formation, and partner choice in

2 response to local $\mathrm{N}$ heterogeneity

3

4 Running title: Response of legumes to nitrogen heterogeneity

6 Xuechun Zhang ${ }^{1 *}$, Lucian Wang ${ }^{1 *}$, Judith Li $^{1}$, Rebecca T. Batstone ${ }^{1}$, Megan E. Frederickson ${ }^{1}$

$7{ }^{1}$ Department of Ecology and Evolutionary Biology, University of Toronto, Toronto, ON,

8 Canada, M5S 3B2

$9 \quad *$ Authors contributed equally

10

11 Corresponding author: Xuechun Zhang

12 University of Toronto

13 Toronto, ON, CAN

14 xuechun.zhang@mail.utoronto.ca 
16 Aims

17 Increases in anthropogenic nitrogen $(\mathrm{N})$ deposition are expected to lead to an overall higher mean and

18 lower variance of $\mathrm{N}$ in the soil, which may disproportionately affect leguminous plants that acquire $\mathrm{N}$

19 both symbiotically via rhizobia and abiotically from soil. Here, we investigate the effects of changing N-

20 heterogeneity at a fine spatial scale on the legume-rhizobium symbiosis.

\section{$21 \quad$ Methods}

22 We used a split-root system to introduce local soil N-heterogeneity, while maintaining the same overall

23 plant-level amount of N. We treated root halves of five inbred lines of Medicago truncatula (HapMap

24 lines 267, 270, 276, 279, and 313) with 50\%-50\%, 20\%-80\%, 10\%-90\%, or 2\%-98\% N and inoculated

25 them with two Ensifer meliloti strains that differ in N-fixation ability.

\section{Results}

27 Although shoot biomass was unaffected by N-heterogeneity, plant lines adjusted their relative

28 investments in nodulation versus root proliferation to optimize $\mathrm{N}$-acquisition; high- $\mathrm{N}$ root halves tended

29 to invest more into root proliferation, while low-N root halves invested more into nodule formation. We

30 detected hidden plasticity in partner choice: although all plants formed more nodules with the more

31 effective $\mathrm{N}$-fixing strain, roots experiencing greater N-limitation increased preference for effective $\mathrm{N}$ -

32 fixing rhizobia. Furthermore, there was significant variation among plant lines in root proliferation and

33 nodulation responses to $\mathrm{N}$-heterogeneity.

\section{Conclusion}

35 In response to N-heterogeneity, $M$. truncatula exhibited phenotypic plasticity in root proliferation,

36 nodulation, and partner choice at the local half-root level. We suggest that plasticity in response to 
37 rhizosphere conditions makes legumes potentially resilient to changes in N-heterogeneity, particularly in 38 a time of anthropogenic $\mathrm{N}$ deposition.

39

40 Keywords: nitrogen deposition, legume-rhizobium symbiosis, Medicago truncatula, Ensifer meliloti, 41 nitrogen acquisition, root foraging, nodulation, partner choice, mutualism 
43 Bioaccessible forms of nitrogen $(\mathrm{N})$ such as nitrate or ammonia often limit terrestrial plant growth

44 (Vitousek et al. 1997). Anthropogenic $\mathrm{N}$ deposition via runoff or atmospheric $\mathrm{N}$ emissions increases

45 overall soil $\mathrm{N}$ availability and significantly impacts plant communities by reducing species diversity

46 (Bobbink et al. 2010; Moreau et al. 2015). This species loss is often non-random, as N-efficient species

47 are subjected to greater interspecific competition from species ordinarily limited by N (Walter et al. 2017;

48 Gilliam et al. 2016). Moreover, this deposition can also result in the loss of N-heterogeneity, coined the

49 N-homogeneity hypothesis (Gilliam 2006), and is likely to continue as a result of future anthropogenic

50 activities (Lamarque et al. 2013; Gilliam et al. 2019). Research in support of the N-homogeneity

51 hypothesis suggests that the spatial heterogeneity of $\mathrm{N}$ and other resources affects plant community

52 composition at a large scale, but the sensitivity of plant communities is modulated by the spatial grain of

53 heterogeneous patches (Hutchings et al. 2003). In addition to impacting plant communities, changes in

54 soil $\mathrm{N}$ have been shown to affect soil microbial communities, with increased $\mathrm{N}$ reducing plant carbon

55 allocation to root microbes (Carara et al. 2018). Of particular concern is how a shift in soil N-

56 heterogeneity may impact plant species that rely on microbial partners for nutrients (Bobbink et al. 2010;

57 Gilliam et al. 2019), yet we know relatively little about the effects of altered N-heterogeneity on

58 symbiotic N-fixing microbes and their host plant species.

As an additional means to acquire $\mathrm{N}$, legumes such as Medicago truncatula have evolved a

60 symbiosis with $\mathrm{N}$-fixing bacteria called rhizobia that are capable of converting atmospheric nitrogen $\left(\mathrm{N}_{2}\right)$

61 into plant-usable forms. In return, rhizobia reside within specialized nodules on plant roots and receive a

62 carbon source from their host. The legume-rhizobium symbiosis has been described as one of the most

63 ecologically and economically important $\mathrm{N}$-fixing symbiotic associations, particularly for its relevance to

64 agricultural production (Wagner 2011) and for understanding mutualism evolution (Heath and Tiffin

65 2007). However, this symbiosis exhibits a great degree of plasticity in response to a variety of biotic and

66 abiotic factors including variation in the N-fixing ability of different rhizobium strains (Parker 1995;

67 Thrall et al. 2000; Heath and Tiffin, 2007) and the availability and distribution of nutrients within the soil, 
as often demonstrated by split-root experiments (Ruffel et al. 2008; Jeudy et al. 2010; Laguerre et al.

69 2012; reviewed in Larrainzar et al. 2014). The legume-rhizobium symbiosis is particularly sensitive to

70 shifts in soil $\mathrm{N}$ availability, and although several previous studies have investigated how changes in mean

71 soil $\mathrm{N}$ affect the symbiosis, we know relatively little about the effects of altered N-heterogeneity on this

72 important interaction.

73 Legumes are capable of optimizing $\mathrm{N}$ acquisition under changing $\mathrm{N}$ conditions in several ways.

74 First, legume roots can "forage" for $\mathrm{N}$ in $\mathrm{N}$-rich patches in the soil, such that roots proliferate more in

75 high- than low-N patches (Robinson et al. 1999; Forde and Lorenzo 2001; Ruffel et al. 2008; Ruffel et al.

76 2011; Batstone et al. 2017). Second, roots downregulate new nodule formation in high-N environments

77 (Streeter and Wong 1988; reviewed in Carroll and Mathews 1990; Bollman and Vessey 2006; Kassaw et

78 al. 2015), suggesting that additional nodulation is costly when a plant has sufficient N. Nodulation is not

79 only regulated systemically but also locally, whereby $\mathrm{N}$-supplied root sections form fewer nodules

80 compared to N-limited sections (Blumenthal et al. 2006; Jeudy et al. 2010, Lin et al. 2018). These results

81 suggest that not only can legumes optimize $\mathrm{N}$ acquisition under changing mean $\mathrm{N}$ conditions, but also

82 under heterogeneous soil $\mathrm{N}$ conditions. Finally, when faced with rhizobia that vary in their quality as N-

83 fixing symbionts, legumes can optimize $\mathrm{N}$ uptake by preferentially associating with or allocating

84 resources to more effective rhizobium strains, traits often termed "partner choice" or legume "sanctions,"

85 respectively (Bull and Rice 1991; Kiers et al. 2003; Heath and Tiffin 2009; Laguerre et al. 2012; reviewed

86 in Frederickson 2013). For example, Medicago truncatula forms $\sim 63 \%$ more nodules with an effective

87 rhizobium strain (Ensifer meliloti 1022) than with an ineffective strain (Ensifer meliloti 1021) (Batstone

88 et al. 2017). Whether legumes can simultaneously adjust root proliferation, nodulation, and partner choice

89 in response to $\mathrm{N}$-heterogeneity remains to be tested.

90 The addition of soil $\mathrm{N}$ is thought to impact the legume-rhizobium symbiosis in several ways.

91 Within the lifespan of a plant, soil $\mathrm{N}$ addition increases plant fitness and decreases overall nodulation

92 (Thomas et al. 2000; Salvagiotti et al. 2008; Zhang et al. 2011), but does not appear to affect the ability of

93 plants to "choose" effective N-fixing rhizobia; the ratio of effective to ineffective N-fixing rhizobia did 
94 not significantly differ between plants growing under N-limited versus N-rich conditions (Regus et al.

95 2014; Grillo et al. 2016). On the other hand, the long-term addition of $\mathrm{N}$ fertilizer to field plots over 22

96 years resulted in the evolution of ineffective $\mathrm{N}$-fixing rhizobia (Weese et al. 2015), either because

97 legumes evolved to rely less on rhizobia as a N source, thus relaxing partner choice (Kiers et al. 2007), or

98 because selection favored the evolution of less beneficial rhizobia that can still nodulate plants but

99 provide less $\mathrm{N}$ in return (Klinger et al. 2016). These previous studies examined the effects of changing

100 mean soil $\mathrm{N}$ levels; to our knowledge, no study has examined the effects of changing soil $\mathrm{N}$ heterogeneity

101 on nodulation and partner choice. While mean soil $\mathrm{N}$ is predicted to increase over the long term (Bobbink

102 et al. 2010), soil $\mathrm{N}$ heterogeneity is likely to fluctuate much more rapidly, and could have important, yet

103 unaccounted for, consequences on the legume-rhizobium symbiosis (Galloway et al. 2004, Gilliam 2006).

104 We conducted a split-root experiment using five lines of the model legume Medicago truncatula

105 and two strains of rhizobia, one ineffective and one effective at fixing N (E. meliloti 1021 and E. meliloti

106 1022, respectively). We chose the five lines based on the results of a previous study (Batstone et al. 2017)

107 that demonstrated that M. truncatula genotypes vary in traits such as partner choice; the five $M$.

108 truncatula lines studied here span the full range of trait values. By holding total soil $\mathrm{N}$ available to each

109 plant constant while changing the proportion of soil $\mathrm{N}$ available to each half-root, we tested whether

110 increasing N-heterogeneity affects several key symbiosis traits, specifically plant performance, root

111 growth, nodulation, and partner choice. This topic is of particular relevance, given the ongoing changes to

112 the global $\mathrm{N}$ landscape from atmospheric $\mathrm{N}$ deposition and other anthropogenic $\mathrm{N}$ inputs that could

113 reduce $\mathrm{N}$ heterogeneity and potentially, plant diversity (Gilliam 2006). We predicted that plants should to

114 be able to compensate for differences in N-heterogeneity between treatments, with no difference in plant

115 performance, by optimizing abiotic and symbiotic N-uptake. Specifically, we predicted that with

116 increasing $\mathrm{N}$-heterogeneity, root halves experiencing greater $\mathrm{N}$ should invest relatively less into

117 nodulation with the effective N-fixing strain, consistent with the reduced dependency on rhizobia in high-

118 N environments found in other experiments (Thomas et al. 2000; Salvagiotti et al. 2008; Zhang et al. 
119 2011). Our study is the first to use a split-root technique to investigate how legumes optimize both 120 symbiotic and abiotic $\mathrm{N}$-uptake under varying degrees of $\mathrm{N}$-heterogeneity.

\section{MATERIALS AND METHODS}

\section{Study system}

124 Medicago truncatula, barrel medic, is an annual legume native to the Mediterranean region and

125 commonly used in legume-rhizobium experiments. We inoculated M. truncatula with two strains of the 126 rhizobium Ensifer meliloti (Em1021 and Em1022) that differ in their effectiveness as N-fixers.

127 Inoculation with Em1022 alone results in almost 40\% greater plant biomass than inoculation with

128 Em1021 (Batstone et al. 2017), and Em1022 fixes around three-times as much nitrogen on M. truncatula

129 A17 compared to Em1021 (Terpolilli et al. 2008). We received Em1021 isolates from Turlough Finan at

130 McMaster University, Canada, and Em1022 isolates from Jason Terpolilli at Murdoch University,

131 Australia. We prepared 480 M. truncatula seeds from five inbred lines (HapMap (HM) lines 267, 270,

132 276, 279, and 313) obtained from the Medicago HapMap Project

133 (http://www.medicagohapmap.org/hapmap/germplasm). The five lines we used were originally collected

134 from Algeria (HM lines 267 and 276), Portugal (HM line 270), Morocco (HM line 279), and an

135 introduced population in Canada (HM line 313), and then selfed to generate seed stocks provided to us by 136 the HapMap Project. We specifically chose these lines because they were included in a previous split-root 137 experiment (Batstone et al. 2017) that, upon reanalysis (see results), found significant variation in each 138 line's ability to both forage for $\mathrm{N}$ in the soil when rhizobia were absent, and to preferentially associate 139 with the higher-quality strain when $\mathrm{N}$-fertilizer was absent.

\section{Plant growth setup}

141 Seed preparation was staggered over 12 days. Each day, an equal number of seeds from each of the five 142 lines was processed (i.e., 8 replicates per line per day), giving us a total of 40 plants per day. Following 143 the split-root protocol of Kassaw and Frugoli (2012) and Batstone et al. (2017), we scarified and surface 144 sterilized the seeds, and after a week of growth over Fahräeus agar, we cut the shoot-root junction to 
145 induce the growth of separate root halves. We then planted successful split-root halves into a system of

146 paired Cone-tainers ${ }^{\mathrm{TM}}$ (Stuewe \& Sons, Tangent, OR, USA) attached side by side. Each half-root grew in

147 its own isolated soil environment, but they shared aboveground plant parts, allowing us to compare both

148 the local and systemic responses to changing $\mathrm{N}$ heterogeneity. We used sterilized washed river sand (New

149 Canadian Lumber, Toronto, Canada) as a substrate for root growth, and plugged the bottom of each Cone-

150 tainer ${ }^{\mathrm{TM}}$ with clean polyester cotton to prevent sand from draining (Supp. Info. Methods S1 and S2). We

151 harvested a total of 338 plants that successfully generated split-roots and survived until harvest, averaging

15217 replicates per line per treatment. Of these, we scored nodule occupancy on 128 plants, an average of

153 six replicates per line per treatment. We cultured bacteria from a total of 1,743 nodules, but analyzed data

154 from only the 1,095 that were unambiguously scored as either Em1021 or Em1022, excluding 52 mixed

155 nodules $(4.52 \%$ of all nodules scored).

\section{$156 \quad$ N-heterogeneity treatments}

157 We randomly assigned plants to N-heterogeneity treatments that varied in the degree of soil $\mathrm{N}$ available to 158 each half-root. In other words, each half-root received a different $\mathrm{N}$ concentration, even though the total $159 \mathrm{~N}$ available to both halves was the same across all treatments (3.13 mM, as in Batstone et al. 2017). We 160 used four different N-heterogeneity treatments, corresponding to $50 \%$ and $50 \%$ of the total $\mathrm{N}$ distributed 161 between the two root halves for the control, then $80 \%$ and $20 \%, 90 \%$ and $10 \%$, and $98 \%$ and $2 \%$ 162 respectively (exact recipes in Supplementary Information). Each root half in the 50:50 treatment was 163 randomly designated as a 'high-N' or 'low-N' root half for statistical analyses, but they received an 164 identical amount of fertilizer. To isolate the effects of $\mathrm{N}$ only, we kept calcium and potassium constant 165 among fertilizers to ensure that these other macronutrients would not affect root responses (Moreau et al. 166 2008). Autoclaved fertilizers were poured into sterilized $50 \mathrm{~mL}$ Falcon Tubes (Corning Life Sciences)

167 that were then securely attached to the bottom of each Cone-tainer ${ }^{\mathrm{TM}}$, and a sterilized wick (Blueline

168 polypropylene rope, $3 / 8$-in diameter) was used to span from three-quarters of the way into the Cone169 tainer ${ }^{\mathrm{TM}}$ to the very bottom of the Falcon tube below. Thus, each plant received two Falcon tubes filled 170 with the same (control) or different fertilizers corresponding to each treatment. Fertilizer was consistently 
171 wicked up into the soil from the attached Falcon tube, and we added additional fertilizer of the same

172 treatment whenever it ran low to ensure a constant supply (Supp. Info. Methods S3). In our experiment,

173 each half-root received a mixed inoculum of both E. meliloti 1021 and E. meliloti 1022 (see details

174 below). For comparison, we also re-analyzed data from Batstone et al. (2017) to assess how the same five

175 plant lines $(267,270,276,279$, and 313) proliferated their root systems in response to $80 \%$ versus $20 \% \mathrm{~N}$

176 in the absence of rhizobia, and how they formed nodules with an effective (Em1022) or ineffective

177 (Em1021) N-fixing strain when growing in a split-root system in the absence of additional $\mathrm{N}$ fertilizer

178 (Fig. S1).

179 Rhizobia inoculation

180 Rhizobia strains were individually streaked onto solid Tryptone Yeast (TY) medium, and a single

181 individual colony was chosen to be inoculated into liquid TY medium for three days in a shaking

182 incubator set to $29^{\circ} \mathrm{C}$ and $200 \mathrm{rpm}$. We recorded the $\mathrm{OD}_{600}$ of each strain to make sure growth was

183 consistent across days $\left(\mathrm{OD}_{600} \sim 0.1\right)$, and then created a 2:1 mix of Em1021:Em1022 strains, providing

184 each plant with $1 \mathrm{~mL}$ of inoculum in total. We used a higher proportion of Em1021 because Em1022 is

185 better at forming nodules with M. truncatula (Terpolilli et al. 2008), and will often be the only strain

186 present in nodules if Em1021:Em1022 inoculation ratios are too low (Batstone et al. 2017) (Supp. Info.

187 Methods S4). Plants then grew in a growth chamber set to $23{ }^{\circ} \mathrm{C} / 18{ }^{\circ} \mathrm{C}$ day/night temperature, $70 \%$

188 humidity, and $300 \mu \mathrm{mol} \mathrm{m}-2 \mathrm{~s}-1$ photosynthetically active radiation (PAR) for a total of 31 days post-

189 inoculation; plants were approximately two months old at this point, after including the time required for

190 generating split-roots. At the end of this period we harvested all plants, and dissected up to five nodules

191 per root half to later measure strain occupancy (Supp. Info. Methods S5). Previously, total nodule

192 biomass was found to account for less than $10 \%$ of total root biomass, indicating that excising a

193 maximum of five nodules would represent only a small portion of root biomass (Jeudy et al. 2010,

194 supplementary information). On average, we removed 0.43 more nodules from low-side roots compared

195 to high-side roots. There was an average of 2.68 and 2.10 nodules remaining on the low-N and high-N

196 root halves respectively, constituting a minimal effect on root biomass comparisons. Finally, we separated 
197 the shoot from the remaining two root sections, dried them in an oven set to $60{ }^{\circ} \mathrm{C}$ for three days, and

198 measured the dried biomass of each of the parts.

199 Nodule occupancy

200 Dissected nodules were thoroughly dried in vials filled with silica gel and cotton on top, and stored at

$2014{ }^{\circ} \mathrm{C}$ to prevent degradation until they were processed. After imbibing overnight in distilled water, we

202 surface-sterilized nodules using ethanol (15 s), bleach (15 s), and five changes of distilled water to

203 remove bleach, and then crushed each individual nodule and streaked its contents onto a solid TY media

204 plate. After three days of growth in an incubator set to $29{ }^{\circ} \mathrm{C}$, we identified the rhizobium strain contained

205 inside each nodule based on colony morphology; Em1021 forms small, isolated opaque colonies, while

206 Em1022 forms large, mucoid colonies. In addition to plates that clearly showed either Em1021 or

207 Em1022, we noted plates with insufficient growth or both strains (i.e., mixed nodules) (Supp. Info.

208 Methods S6).

209 Statistical analyses

210 To investigate the effects of N-heterogeneity on several key symbiosis-related traits at both the whole-

211 plant and local half-root levels, we used a generalized linear mixed model (GLMM) framework executed

212 in R using the lme4 package (Bates et al. 2015). For whole-plant traits (shoot biomass, total nodule

213 number, root biomass, and partner choice), we included the main and interactive fixed effects of N-

214 heterogeneity treatment (four levels, ordered by increasing heterogeneity) and plant line (five levels), as

215 well as the random effects of batch (i.e., day) and tray (nested within batch). Partner choice in this case

216 was calculated by dividing the number of nodules a plant formed with the effective N-fixing strain by the

217 total number of nodules formed with both strains. For half-root responses (root biomass, nodule number),

218 we included the fixed main and interactive effects of $\mathrm{N}$-heterogeneity treatment, plant line, root-half (i.e.,

219 high-N or low-N, nested within treatment), and either nodule number or root biomass as a covariate,

220 respectively, as well as the random effects of batch, tray (nested within batch), and plant ID (nested

221 within tray). To examine partner choice at the half-root level, we used the same model as for nodule

222 number, except that we additionally included the main and interactive effects of strain (two levels, either 
223 Em1022 or Em1021). For models with nodule number as a response, we additionally included an 224 observation-level term as a random effect to account for overdispersion (Elston et al. 2001; Harrison

225 2014). We determined the best-fit probability distribution of each model by choosing the one that gave

226 the lowest AIC value. The analysis of deviance used Wald Chi-squared tests (CAR package in R; Fox and

227 Weisberg 2011) with type III sums of squares to make sure results did not depend on the order in which

228 model terms were tested. We checked model fit by plotting scaled residuals versus fitted values. Finally,

229 we used the lsmeans package in R (v.2.25; Lenth et al. 2015) to conduct post-hoc analyses based on least

230 squares means. Specifically, we compared root halves (i.e., low- versus high-N) in each treatment over

231 plant lines, as well as for each treatment within plant lines using Dunnett (1995)'s contrasting method.

233 RESULTS

234 Whole-plant results

235 Shoot biomass was similar across $\mathrm{N}$-heterogeneity treatments $(\mathrm{p}=0.612)$, but differed significantly among 236 plant lines ( $\mathrm{p}<0.001$; Fig. S2). Plant line 270 in particular did not germinate well and we discovered 237 during harvest that many plants established only one successful root half. Overall, plants formed many

238 more nodules with the effective N-fixing strain than with the ineffective strain, with an average Em1022239 occupancy rate of $76.5 \%( \pm 1.60 \% \mathrm{SE})$, but there was no effect of $\mathrm{N}$-heterogeneity treatment on partner 240 choice at the whole-plant level nor a significant difference among lines (see Fig. S2d). We also found a 241 non-significant $(\mathrm{p}>0.1)$ main effect of $\mathrm{N}$-heterogeneity on total root biomass and nodule number.

242 Similar to our shoot biomass results, plant lines significantly differed $(p<0.001)$ in terms of total root 243 biomass and nodule number $(\mathrm{p}<0.001)$, but not $\mathrm{N}$-heterogeneity treatment at the whole-plant level (Fig.

244 S2, Table S1).

\section{Half-root results}

246 In contrast to whole-plant traits, we observed many differences among N-heterogeneity treatments at the

247 half-root level. We found a significant interaction between $\mathrm{N}$-heterogeneity treatment and root half for 248 root biomass $(\mathrm{p}<0.05$, Table $\mathrm{S} 2)$; independent of plant line, as $\mathrm{N}$-heterogeneity increased, high-N root 
249 halves grew larger than low-N root halves, although the difference between root halves was non-

250 significant in the 10:90 treatment (Fig. 1 "All lines" panel). Moreover, the significant three-way

251 interaction among N-heterogeneity treatment, root half, and plant line suggests that plant genotypes

252 differed in their ability to respond to N-heterogeneity via root proliferation ( $\mathrm{p}<0.01$, Table S2); plant line

253279 clearly showed the expected response of increasing root biomass as $\mathrm{N}$ became increasingly available

254 on the high-N side, while plant line 270 did not show any trend with increasing N-heterogeneity (Fig. 1).

255 Similarly, root halves tended to form more nodules as they became more N-limited, compared to

256 when they were locally supplied with greater N concentrations (Fig. 2 "All lines" panel). Again, we found

257 a significant three-way interaction among line, N-heterogeneity treatment, and root half $(\mathrm{p}<0.01$, Table

258 S2), suggesting that plant lines varied in their ability to regulate nodulation in response to N-

259 heterogeneity; plant line 313 showed an increasing, although saturating, response to N-heterogeneity on

260 the low-N side, while other lines, such as 270 and 279, did not show much difference between root halves

261 with increasing N-heterogeneity (Fig. 2). We also found a significant three-way interaction among root

262 biomass, $\mathrm{N}-$ heterogeneity treatment, and root half for number of nodules $(\mathrm{p}<0.01$, Table S2); with

263 increasing N-heterogeneity, there were correspondingly greater differences between low-N and high-N

264 root halves in the number of nodules formed per unit of root biomass (Fig. 3). Specifically, high-N root

265 halves tended to form fewer nodules per unit root biomass as local $\mathrm{N}$ availability increased (Fig. 3). In

266 addition, the magnitude of this difference depended on rhizobium strain (i.e., four-way interaction among

267 root biomass $\mathrm{x}$ treatment $\mathrm{x}$ root half $\mathrm{x}$ strain, $\mathrm{p}<0.001$, Table $\mathrm{S} 3$ ), and was mostly driven by the effective

268 N-fixing strain Em1022 (Fig. 4). Finally, we found a significant three-way interaction among N-

269 heterogeneity treatment, root half, and rhizobium strain $(\mathrm{p}<0.05$, Table S3), indicating that root halves

270 formed significantly more nodules with the effective N-fixing strain Em1022 when they were more N-

271 limited, while they formed similar numbers of nodules with the ineffective strain Em1021 across N-

272 heterogeneity treatments (Fig. 4). In other words, low-N root halves exerted stronger partner choice when

$273 \quad \mathrm{~N}$ was more limiting. 
Re-analyzing data from Batstone et al. (2017), we found that in the absence of rhizobia, high-N

275 root halves also had higher root biomass than low-N root halves (Fig. S1 B, Table S4). Specifically, there

276 was a significant effect of treatment $(20 \%$ versus $80 \% \mathrm{~N})$ on root biomass $(\mathrm{p}<0.001)$, and a significant

277 interaction effect between treatment and plant line on root biomass $(\mathrm{p}<0.05)$, suggesting that plant lines

278 differ in their ability to forage for $\mathrm{N}$. When rhizobia were present and N-fertilizer absent, roots inoculated

279 with the effective $\mathrm{N}$-fixer Em1022 formed more nodules overall ( $\mathrm{p}<0.001)$, and a significant interaction

280 between treatment and plant line on nodule number was evident $(\mathrm{p}<0.001)$, suggesting that plant lines

281 differed in their ability to preferentially associate with the effective N-fixer Em1022 (Fig. S1 D). Our

282 analysis revealed lines 313 and 267 to be the worst root foragers, but the most selective in their

283 associations, forming most of their nodules with the more effective N-fixing strain (Fig. S1 D). In

284 contrast, line 279 was best at root foraging, but was indiscriminate, forming similar nodule numbers with

285 both strains (Fig. S1 B, D). Lines 276 and 270 were moderate root foragers, but formed similar or more

286 nodules with the ineffective N-fixing strain, respectively (Fig. S1 B, D).

\section{DISCUSSION}

\section{Plant responses to N-heterogeneity}

289 Overall, we found that legumes can maintain performance even under extreme N-heterogeneity by finely

290 balancing local root proliferation and nodulation in a strain-specific manner. Despite increasing N-

291 heterogeneity, aboveground plant biomass remained constant as half-roots adjusted their investment in

292 growth versus nodule formation. High-N root halves foraged for abiotic $\mathrm{N}$ by increasing root proliferation

293 (Fig. 1), while low-N root halves foraged for symbiotic $\mathrm{N}$ by making more nodules (Fig. 2). While our

294 findings of root foraging and nodulation regulation in response to $\mathrm{N}$ fertilizer are not new (Streeter 1985,

295 Carroll and Mathews 1990, Salvagiotti et al. 2008), our experiment is the first to demonstrate that as N-

296 heterogeneity increases, plants form more nodules with a more effective N-fixer (Em1022) on N-starved

297 root halves (Fig. 4), showing that partner choice can respond to local N conditions. Our results are likely

298 conservative, as splitting the roots of plants had some adverse effects on growth and development that

299 could dampen the magnitude of differences observed among N-heterogeneity treatments (Batstone et al. 
2017). Our split-root study revealed that despite differences in overall vigor among lines (some lines

301 outperformed others, and lines displayed varying magnitude of responses to N-heterogeneity), all plant

302 lines were somewhat able to modulate local root responses, suggesting that M. truncatula could be 303 resilient to changing $\mathrm{N}$ regime.

Our study is consistent with numerous previous findings (e.g. Streeter 1985; also reviewed in Streeter and Wong 1988) that show N-limited roots upregulate nodulation relative to N-supplied roots;

307 increase with increasing N-heterogeneity, but saturates in the most extreme N-heterogeneity treatment

308 (Fig. 2), perhaps because roots on the N-limited side are comparatively smaller (Fig. 1), and thus, space

309 constraints put an upper limit on nodulation. By regressing nodule number against root biomass, we found

310 that the nodules formed per unit root biomass depended on both N-heterogeneity treatment and rhizobium

311 strain (Figs. 3 and 4, Table S3); as N-heterogeneity increased, roots experiencing greater N-limitation

312 made more nodules per unit root biomass with the effective $\mathrm{N}$-fixing strain Em1022, but the number of

313 ineffective Em1021 nodules remained relatively constant across treatments (Fig. 4, Table S3). Because

314 we inoculated half-roots with both rhizobium strains in all $\mathrm{N}$-heterogeneity treatments, we cannot

315 determine how each strain may have altered root responses to N-heterogeneity independently. However,

316 our results clearly show that $M$. truncatula optimizes $\mathrm{N}$-acquisition by adjusting root growth and

317 nodulation with the effective $\mathrm{N}$-fixing strain when $\mathrm{N}$ is limiting. The upregulation of nodulation on $\mathrm{N}$ -

318 limiting roots further supports that $\mathrm{N}$ plays a role in modulating nodule formation and warrants further

319 investigation into pathways that affect the number and distribution of nodules on the root system.

320 The novelty of our study is that we uncovered hidden plasticity in partner choice at the half-root

321 level; root halves experiencing greater N-limitation not only exhibited greater nodulation relative to root

322 biomass, but this was driven by increased partner choice (Figs. 3 and 4, Table S3). At the whole-plant

323 level, our results reaffirm that M. truncatula exhibits significant partner choice when presented with both

324 effective and ineffective rhizobium strains (e.g., Heath and Tiffin 2009; Gubry-Rangin et al. 2010;

325 Batstone et al. 2017). But, plants did not exhibit plasticity in partner choice in response to N- 
heterogeneity at the whole-plant level (Table S1), reaffirming previous studies that found consistent levels

327 of partner choice when plants were exposed to different mean amounts of $\mathrm{N}$ in the soil (Laguerre et al.

328 2012; Regus et al. 2014; Grillo et al. 2016). However, by examining the local root-level responses to

329 changing $\mathrm{N}$ conditions, we indeed find that plants can modulate the strength of partner choice by forming

330 more nodules with a more effective $\mathrm{N}$-fixer when $\mathrm{N}$ is limiting (Fig. 4). Furthermore, our results suggest

331 that abiotic N-heterogeneity may change the spatial distribution of rhizobia in the rhizosphere; given that

332 high-N half-roots nodulated significantly less overall, we expect rhizobia (and especially beneficial

333 rhizobia) to reach higher densities in low-N patches. Future studies would benefit from assessing the fine-

334 scale spatial distribution of rhizobia in the soil as it relates to $\mathrm{N}$-availability.

\section{Genetic variation in plant responses to $\mathbf{N}$-heterogeneity}

336 Most previous experiments examining M. truncatula's ability to optimize N-uptake focused on a single

337 plant line or used an additional mutant line (e.g., Ruffel et al. 2008; Jeudy et al. 2010; Laguerre et al.

338 2012). The five plant lines we used were previously found to vary in their ability to forage for $\mathrm{N}$ in the

339 soil and preferentially associate with an effective $\mathrm{N}$-fixer when these traits were measured individually

340 (Batstone et al. 2017; Fig. S1). Our experiment uncovered significant genetic variation in root foraging

341 and nodulation when both $\mathrm{N}$ fertilizer and rhizobia were present (Table S2). For example, line 270

342 exhibited almost no difference in root biomass or nodulation even at the most extreme N-heterogeneity

343 treatment (Figs. 1,2), indicating that some lines are either unable to cope with $\mathrm{N}$ heterogeneity effectively

344 or are using different mechanisms to cope with N-heterogeneity. In contrast, line 279 demonstrated

345 effective root foraging consistent with previous studies (e.g., Hodge et al. 1999; Robinson et al. 1999;

346 Batstone et al. 2017), whereby N-supplied roots grew increasingly larger as N-heterogeneity increased

347 (Fig. 1). Our study uncovered significant variation among M. truncatula lines in their ability to plastically

348 respond to N-heterogeneity, and significant differences in fitness (shoot biomass) among lines, but no

349 significant line $\mathrm{x}$ treatment effect on plant fitness; e.g., the least plastic and least fit line (270) performed

350 equally poorly in all N-heterogeneity treatments. We might have expected line 270 to outperform more

351 plastic lines in the 50:50 treatment, when other plant lines could not capitalize on their ability to adjust $\mathrm{N}$ 
acquisition in response to N-heterogeneity, but the costs of phenotypic plasticity are notoriously difficult

353 to measure (Auld et al. 2010) and measuring selection on plasticity in M. truncatula would likely require

354 phenotyping many more than five plant lines across multiple N-heterogeneity environments.

Comparing results from the same five lines between experiments (i.e., present study versus Batstone et al. 2017) revealed several similarities, but also obvious differences. First, when we reanalyzed published data from Batstone et al. (2017) on root foraging in the absence of rhizobia, we similarly found that line 279 was best at root foraging while the other plant lines only marginally increased root growth under high-N conditions (Fig. S1 B), suggesting that line 279's superior root foraging ability is not altered significantly by the presence of rhizobia. In contrast, plant line 313 showed much greater root proliferation into 80\%-N when rhizobia were present (Fig. 1) than absent (Fig. S1 B), supporting other studies that find rhizobia can alter the root foraging capabilities of the plant (e.g., Goh et al. 2016). The best root forager (i.e., 279) and choosiest plant line (i.e., 313) from Batstone et al. (2017) were also the top two performing lines in our present study (Fig. S2A), suggesting that effectively coping with N-heterogeneity may be achieved through alternative strategies, such as specializing in abiotic or symbiotic $\mathrm{N}$-acquisition. In our present study, we found that plant lines differed in their plastic responses

367 to increasing heterogeneity, supporting a theory of alternative strategies for coping with N-heterogeneity

368 (Fig. 1, Fig. 2, Table S2). A major difference between the two experiments, however, is that in contrast to 369 Batstone et al. (2017), we did not find significant genetic variation in partner choice (Table S3); all lines 370 tended to upregulate nodulation with the more effective $\mathrm{N}$-fixer when roots became increasingly N-

371 limited (Fig. 4). This difference is likely due to the fact that in Batstone et al. (2017), strains were

372 inoculated separately onto root halves, whereas in our study, both strains were inoculated onto both root

373 halves. Eliminating spatial separation between strains permits antagonistic strain-strain interactions, and

374 could modify the plant's ability to discriminate between strains, both of which are expected to affect

375 partner choice as evident in the present study.

376 Under environmental shifts in nutrient availability, fixed strategies are at risk of being

377 outcompeted by more flexible genotypes, leading to local and community shifts in genotypic 
composition. In contrast, legumes such as M. truncatula could be more effective at coping with shifting $\mathrm{N}$

379 heterogeneity by fine-tuning both abiotic and symbiotic $\mathrm{N}$-acquisition traits including root foraging,

380 nodulation, and partner choice. The genetic variation we observed in local root responses to N, combined

381 with the accessions and genomic resources available through the Medicago Hapmap project, make $M$.

382 truncatula a good candidate species for understanding the mechanisms that legumes use to cope with

383 changing N conditions. Future studies could utilize many different $M$. truncatula genotypes to address

384 whether $\mathrm{N}$-acquisition traits are under selection, and how N-heterogeneity may alter selection for these

385 traits.

\section{CONCLUSIONS}

387 Given the dramatic rise of agricultural inputs to the global N cycle, understanding the traits and

388 mechanisms that organisms use to better cope with increasing N-heterogeneity is pressing. Here we

389 improved our understanding of how M. truncatula acquires N symbiotically and abiotically under

390 homogeneous versus heterogeneous $\mathrm{N}$ conditions, and our results emphasize the substantial phenotypic

391 plasticity of root investment in both proliferation and strain-specific nodulation. We suggest that this

392 plasticity makes legumes potentially resilient to changes in N-heterogeneity, as evidenced by the similar

393 performance of plants across treatments. More research into the legume-rhizobium mutualism will give us

394 greater insight into the future of mutualistic systems as $\mathrm{N}$ heterogeneity continues to decrease from

395 anthropogenic activities.

\section{ACKNOWLEDGEMENTS}

398 We acknowledge funding from an NSERC Discovery Grant and Discovery Accelerator Supplement 399 (MEF), Ontario Graduate Scholarships (RTB), and the University of Toronto Centre for Global Change 400 Science (LW). For assistance with the experiment, we thank Georgiana Forguson, Daniel Li, Christina 401 Bailey, Kevin Ong, Obaid Mohammad, Farida Samad-Zada, Wenjun Deng, Emily Pryszlak, Nigel 402 Henriques, Armin Vallazza-Margl, Jessie Wang, Selina Hsu, Longxi Lin, Wendy Zhang, Ayesha Ahmad, 
403 Chanel Trac, Annmarie Villanueva, Ray Martinez-Rodriguez, Jessica Santilli, Andrea Sarbu, and

404 Rowaida Hussein. Xuechun Zhang and Lucian Wang also thank Matthew McKinlay for his guidance and 405 insight into the field of biology.

406

407 Conflict of Interest

408 The authors submit that they have no conflicts of interest to declare at this time.

409

410 


\section{REFERENCES}

412 Auld JR, Agrawal AA, Relyea RA (2010) Reevaluating the costs and limits of adaptive phenotypic plasticity. Proc R Soc B 277:503-511.

414 Bates D, Maechler M, Bolker B, Walker S (2015) Fitting linear mixed-effects models using lme4. J Stat $415 \quad$ Software 67:1-48.

416 Batstone RT, Dutton EM, Wang D, Yang M, Frederickson ME (2017) The evolution of symbiont 417 preference traits in the model legume Medicago truncatula. New Phytol 213:1850-1861.

418 Blumenthal JM, Russelle MP, Vance CP (2006) Localized and internal effect of nitrate on symbiotic 419 dinitrogen fixation. Physiol Plantarum 101:59-66.

420 Bobbink R, Hicks K, Galloway J et al (2010) Global assessment of nitrogen deposition effects on 421 terrestrial plant diversity: a synthesis. Ecol Appl 20:30-59.

422 Bollman MI, Vessey JK (2006) Differential effects of nitrate and ammonium supply on nodule initiation, 423 development, and distribution on roots of pea (Pisum sativum). Can J Botany 84:893-903.

424 Bull JJ, Rice WR (1991) Distinguishing mechanisms for the evolution of co-operation. J Theor Biol $425 \quad 149: 63-74$.

426 Carrara JE, Walter CA, Hawkins JS, Peterjohn WT, Averill C, Brzostek ER (2018) Interactions among plants, bacteria, and fungi reduce extracellular enzyme activities under long- term $\mathrm{N}$ fertilization. Glob Change Biol 24:2721-2734

Carroll BJ, Mathews A (1990) Nitrate inhibition of nodulation in legumes. In (Gresshof PM) Molecular biology of symbiotic nitrogen fixation, pp. 159-180. CRC Press, Inc. Boca Raton, Florida. positively associated with fertility in a northern grassland. J Ecol https://doi.org/10.1890/08-1140.1 legume symbiotic performance. Soil Biol Biochem 38:2944-2951. 
437 Elston DA, Moss R, Boulinier T, Arrowsmith C, Lambin X (2001) Analysis of aggregation, a worked example: numbers of ticks on red grouse chicks. Parasitology 122:563-569.

439 Forde B, Lorenzo H (2001) The nutritional control of root development. Plant Soil: 51-68.

440 Fox J, Weisberg S (2011). An R Companion to Applied Regression. Sage Publication. Thousand Oaks, $441 \quad$ California.

442 Frederickson ME (2013) Rethinking mutualism stability: cheaters and the evolution of sanctions. Q Rev $443 \quad$ Biol 88:269-295

444 Galloway JN, Dentener FJ, Capone DG, Boyer EW, Howarth RW, Seitzinger SP, Asner GP ... 445 Vörösmarty CJ (2004) Nitrogen cycles: past, present, and future. Biogeochemistry 70:153-226.

446 Gilliam FS (2006) Response of the herbaceous layer of forest ecosystems to excess nitrogen deposition. J Ecol 94:1176-1191.

448 Gilliam FS, Burns DA, Driscoll CT, Frey SD, Lovett GM, Watmough SA (2019) Decreased atmospheric nitrogen deposition in eastern North America: Predicted responses of forest ecosystems, Environ Pollut 244:560-574

Gilliam FS, Welch NT, Phillips AH, Billmyer JH, Peterjohn WT, Fowler ZK ... Adams, MB (2016) Twenty- five- year response of the herbaceous layer of a temperate hardwood forest to elevated nitrogen deposition. Ecosphere 7:e01250

Goh C, Nicotra AB, Mathesius U (2016) The presence of nodules on legume root systems can alter phenotypic plasticity in response to internal nitrogen independent of nitrogen fixation. Plant Cell Environ 39:883-896.

Grillo MA, Stinchcombe JR, Heath KD (2016) Nitrogen addition does not influence pre-infection partner choice in the legume-rhizobium symbiosis. Am J Bot 103:1763-1770.

\section{Gubry-Rangin C, Garcia M, Béna G (2010) Partner choice in Medicago truncatula-Sinorhizobium} symbiosis. Proc R Soc Lond B 277:1947-1951.

Harrison XA (2014) Using observation-level random effects to model overdispersion in count data in ecology and evolution. PeerJ 2:e616. https://doi.org/10.7717/peerj.616 
Heath KD, Tiffin P (2007) Context dependence in the coevolution of plant and rhizobial mutualists. Proc R Soc Lond B 274:1905-1912.

Heath KD, Tiffin P (2009) Stabilizing mechanisms in a legume-rhizobium mutualism. Evolution 63:652662.

Hodge A, Robinson D, Griffiths BS, Fitter AH (1999) Why plants bother: root proliferation results in increased nitrogen capture from an organic patch when two grasses compete. Plant Cell Environ 22:811-820.

Hodge A, Storer K (2015) Arbuscular mycorrhiza and nitrogen: implications for individual plants through

472 Hutchings MJ, John EA, Wijesinghe DK (2003) Toward understanding the consequences of soil 473 heterogeneity for plant populations and communities. Ecology 84:2322-2334.

474 Jeudy C, Ruffel S, Freixes S et al (2010) Adaptation of Medicago truncatula to nitrogen limitation is 475 modulated via local and systemic nodule developmental responses. New Phytol 185:817-828. 476 Kassaw T, Frugoli JA (2012) Simple and efficient methods to generate split roots and grafted plants useful for long-distance signaling studies in Medicago truncatula and other small plants. Plant Methods. https://doi.org/10.1186/1746-4811-8-38

479 Kassaw T, Bridges JW, Frugoli J (2015) Multiple autoregulation of nodulation (AON) signals identified through split root analysis of Medicago truncatula sunn and rdn1 mutants. Plants 4:209-224.

Kiers ET, Hutton MG, Denison RF (2007) Human selection and the relaxation of legume defences against ineffective rhizobia. Proc R Soc Lond B 274:3119-3126.

Kiers ET, Rousseau RA, West SA, Denison RF (2003) Host sanctions and the legume-rhizobium

485 Klinger CR, Lau JA, Heath KD (2016) Ecological genomics of mutualism decline in nitrogen-fixing 486 bacteria. Proc R Soc Lond B. https://doi.org/10.1098/rspb.2015.2563 
Laguerre G, Heulin-Gotty K, Brunel B et al (2012) Local and systemic N signaling are involved in Medicago truncatula preference for the most efficient Sinorhizobium symbiotic partners. New Phytol 195:437-449.

Larrainzar E, Gil-Quintana E, Arrese-Igor C, Gonzalez EM, Marino D (2014) Split-root systems applied to the study of the legume-rhizobial symbiosis: What have we learned? J Integr Plant Biol 56:1118-

Lamarque JF, Dentener F, McConnell J, Ro C, Shaw M, Vet R ... Nolan, M (2013) Multi-model mean nitrogen and sulfur deposition from the Atmospheric Chemistry and Climate Model

Lenth R (2016) Least-Squares Means: The R Package lsmeans. J Stat Softw 69:1-33.

Lin JS, Li X, Luo ZL, Mysore KS, Wen J, Xie F (2018). NIN interacts with NLPs to mediate nitrate inhibition of nodulation in Medicago truncatula. Nat Plants 4:942.

Moreau D, Pivato B, Bru D, Busset H, Deau F, Faivre C, Matejicek A, Strbik F, Philippot L, Mougel C (2015) Ecology 96:2300-2310.

Moreau D, Voisin AS, Salon C, Munier-Jolain N (2008) The model symbiotic association between Medicago truncatula cv. Jemalong and Rhizobium meliloti strain 2011 leads to N-stressed plants when symbiotic N2 fixation is the main N source for plant growth. J Exp Bot 59:3509-3522.

Parker MA (1995) Plant fitness variation caused by different mutualist genotypes. Ecology 76:15251535.

Regus JU, Gano KA, Hollowell AC, Sachs JL (2014) Efficiency of partner choice and sanctions in Lotus is not altered by nitrogen fertilization. Proc R Soc Lond B. https://doi.org/10.1098/rspb.2013.2587

Robinson D, Hodge A, Griffiths BS, Fitter AH (1999) Plant root proliferation in nitrogen-rich patches confers competitive advantage. Proc R Soc Lond B 266:431-435. 

specific transcriptome responses depending on the nitrogen source in Medicago truncatula. Plant

$514 \quad$ Physiol 146:2020-2035.

515 Ruffel S, Krouk G, Ristova D, Shasha D, Birnbaum KD, Coruzzi GM (2011) Nitrogen economics of root 516 foraging: Transitive closure of the nitrate-cytokinin relay and distinct systemic signaling for $\mathrm{N}$ 517 supply vs. demand. P Natl Acad Sci USA 108:18524-18529.

518 Salvagiotti F, Cassman KG, Specht JE, Walters DT, Weiss A, Dobermann A (2008) Nitrogen uptake, 519 fixation and response to fertilizer N in soybeans: A review. Field Crops Res 108:1-13. https://doi.org/10.1016/j.fcr.2008.03.001

Singleton PW, AbdelMagid HM, Tavares JW (1985) Effects of phosphorus on the effectiveness of strains of Rhizobium japonicum. Soil Sci Soc Am J 49:613-616.

523 Streeter JG (1985) Nitrate Inhibition of Legume Nodule Growth and Activity. Plant Physiol 77:325-328.

524 Streeter J, Wong PP (1988) Inhibition of legume nodule formation and N2 fixation by nitrate. Crit Rev Plant Sci 7:1-23.

Terpolilli JJ, O’Hara GW, Tiwlworth MJ, Howieson JG (2008) The model legume Medicago truncatula A17 is poorly matched for N2 fixation with the sequenced microsymbiont Sinorhizobium meliloti 1021. New Phytol 179:62-66.

Thomas RB, Bashkin MA, Richter DD (2000) Nitrogen Inhibition of Nodulation and N2 Fixation of a Tropical N2-Fixing Tree (Gliricidia sepium) Grown in Elevated Atmospheric CO2. New Phytol 145:233-243.

Thrall PH, Burdon JJ, Woods MJ (2000) Variation in the effectiveness of symbiotic associations between native rhizobia and temperate Australian legumes: interactions within and between genera. J Appl Ecol 37:52-65.

Vitousek PM, Aber JD, Howarth RW, Likens GE, Matson PA, Schindler DW, Schlesinger WH, Tilman

538 Wagner SC (2011) Biological nitrogen fixation. Nature 3:15. 
539 Walter CA, Adams MB, Gilliam FS, Peterjohn WT (2017) Non- random species loss in a forest

540 herbaceous layer following nitrogen addition, Ecology 98:2322-2332.

541 Weese DJ, Heath KD, Dentinger B, Lau JA (2015) Long- term nitrogen addition causes the evolution of $542 \quad$ less- cooperative mutualists. Evolution 69:631-642.

543 Zhang L, Wu D, Shi H, Zhang C, Zhan X, Zhou S (2011) Effects of Elevated CO2 and N Addition on

544 Growth and N2 Fixation of a Legume Subshrub (Caragana microphylla Lam.) in Temperate

545 Grassland in China. PLoS ONE. https://doi.org/10.1371/journal.pone.0026842

546

547 
549 Figure 1: Root foraging depends on N-heterogeneity treatment and plant line. Dry root biomass

550 (least squares means $\pm 1 \mathrm{SE}$ ) of low-N (open symbols) and high-N (filled symbols) root halves in each $\mathrm{N}$ 551 heterogeneity treatment (50:50, 20:80, 10:90, 2:98) for each plant line (from top-left: 270, 276, 267, 313, 552 and 279) and across all plant lines (bottom-right, “All lines”). Symbols above means represent significant $553 \quad(*=$ p-value $<0.05 ; * *=$ p-value $<0.01 ; * * *=$ p-value $<0.001)$ and marginally significant $(\mathbb{\square}=$ p-values 554 between 0.05-0.1) contrasts between root halves at each treatment level (sensu Dunnett 1995). See Table 555 S2 for complete GLMM results.

Figure 2: Nodulation is affected by $\mathbf{N}$-heterogeneity treatment and plant line. Nodule number (least squares means $\pm 1 \mathrm{SE}$ ) of low-N (open symbols) and high-N (filled symbols) root halves in each Nheterogeneity treatment (50:50, 20:80, 10:90, 2:98) for each plant line (from top-left: 270, 276, 267, 313, and 279) and across all plant lines (bottom-right, "all lines"). Symbols above means represent significant $(*=$ p-value $<0.05 ; * *=$ p-value $<0.01 ; * * *=$-value $<0.001)$ and marginally significant $(\mathbf{\square}=$ p-value between 0.05-0.1) contrasts between root halves at each treatment level. See Table S2 for complete GLMM results.

Figure 3: Nodule number per unit root biomass depends on $\mathrm{N}$-heterogeneity treatment.

566 Relationships between nodule number and root biomass for low-N (open symbols) and high-N (filled

567 symbols) root halves in each $\mathrm{N}$-heterogeneity treatment (from left: 50:50, 20:80, 10:90, 2:98). Data from

568 all plant lines and both rhizobium strains were pooled for each treatment. Grey shading represents

569 standard error. Solid and dashed lines show linear regression lines for high-N and low-N root halves,

570 respectively. P-values based on model regression coefficients indicate a significant difference in slope

571 when comparing between root halves at each N-heterogeneity treatment except the control (50:50). See

572 Table S3 for complete GLMM results. 
574 Figure 4: Plasticity in partner choice as roots become more $\mathbf{N}$-limited. The number of Em1021 (left)

575 and Em1022 (right) nodules (least squares \pm 1 SE) on low-N (open symbols) and high-N (filled symbols)

576 root halves in each $\mathrm{N}$-heterogeneity treatment (50:50, 20:80, 10:90, 2:98). Data from all plant lines were

577 pooled for each treatment. Symbols above means represent significant $(*=$ p-value $<0.05 ; * *=$-value $<$

578 0.01) contrasts between root halves. See Table S3 for complete GLMM results.

579

580 


\section{SUPPORTING INFORMATION}

582 Figure S1. Shoot and root responses to fertilizer (A, B) or rhizobia (C, D) in a previous split-root

583 experiment (Batstone et al. 2017). Dry shoot biomass (A) and dry root-half biomass (B) responses (mean

$584 \pm 1 \mathrm{SE}$ ) to $\mathrm{N}$ treatments of $20 \%$ and $80 \%$ of total available $\mathrm{N}$, for low-N and high-N root halves,

585 respectively. Plants in A and B were not inoculated with rhizobia, and remained rhizobium-free

586 throughout the experiment. In contrast, C and D show dry shoot biomass (C) and nodule number (D)

587 responses (mean $\pm 1 \mathrm{SE}$ ) to rhizobia that differ in their ability to fix $\mathrm{N}$, with Em1021 being ineffective and

588 Em1022 being effective. Plants in C and D were given an N-free fertilizer throughout the experiment. See

589 Table S4 for complete GLMM results.

590

591 Figure S2. Whole-plant responses (mean $\pm 1 \mathrm{SE}$ ) with all treatments combined for each plant line. Nodule

592 count and dry root biomass results are pooled from both low-N and high-N root halves. Numbers next to

593 points show sample size for each line. See Table S1 for complete GLMM results.

594

595 Figure S3. Photo of Experimental Setup, displaying M. truncatula in a split-root setup with each root half

596 in a separate Cone-tainer ${ }^{\mathrm{TM}}$ (Stuewe \& Sons, Tangent, OR, USA) attached side by side.

598 Table S1. Analysis of deviance (ANODEV) tables for whole-plant responses, with the main effects of 599 plant line, N-heterogeneity treatment, and their interaction. Random effects included batch and tray.

600 Significant p-values $(<0.05)$ are highlighted in bold.

601

602 Table S2. ANODEV tables for half-root responses, including dry root biomass and nodule number, with 603 main effects of plant line, N-heterogeneity treatment, root half nested within treatment, a covariate (either 604 nodule number or dry root biomass, respectively), and all interactions. Random effects included batch, 605 tray, and plant. Significant p-values $(<0.05)$ are highlighted in bold. Marginally significant p-values $606 \quad(0.05-0.1)$ are italicized. 
608 Table S3. ANODEV table for partner choice, with main effects of plant line, N-heterogeneity treatment, 609 root half nested within treatment, dry root biomass as a covariate, strain, and all interactions. Random 610 effects included batch, tray, plant. Significant p-values $(<0.05)$ are highlighted in bold. Marginally

611 significant p-values (0.05-0.1) are italicized.

612

613 Table S4. ANODEV table based on data from a previous half-root experiment (Batstone et al. 2017) that

614 included dry shoot and root biomass and nodule number as responses, with the main effects of plant line, 615 treatment (20\% or 80\%-N; inoculated with Em1021 or Em1022) and their interaction. Random effects

616 included tray and plant (root biomass model only). Significant p-values $(<0.05)$ are highlighted in bold. 617

618 Methods S1-6. Details of split-root generation, making up fertilizers, rhizobia inoculation, harvesting 619 plants, and determining nodule occupancy. 


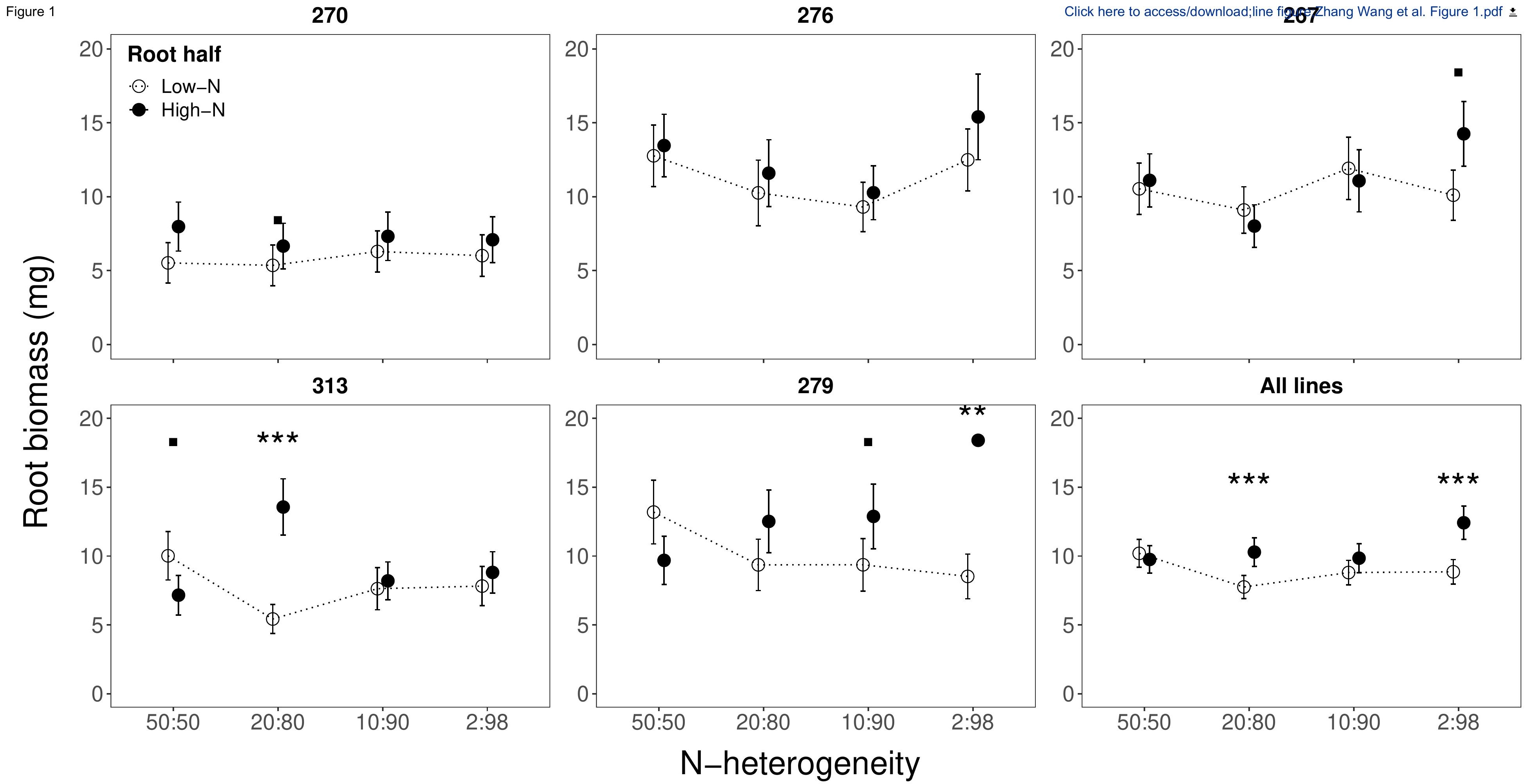




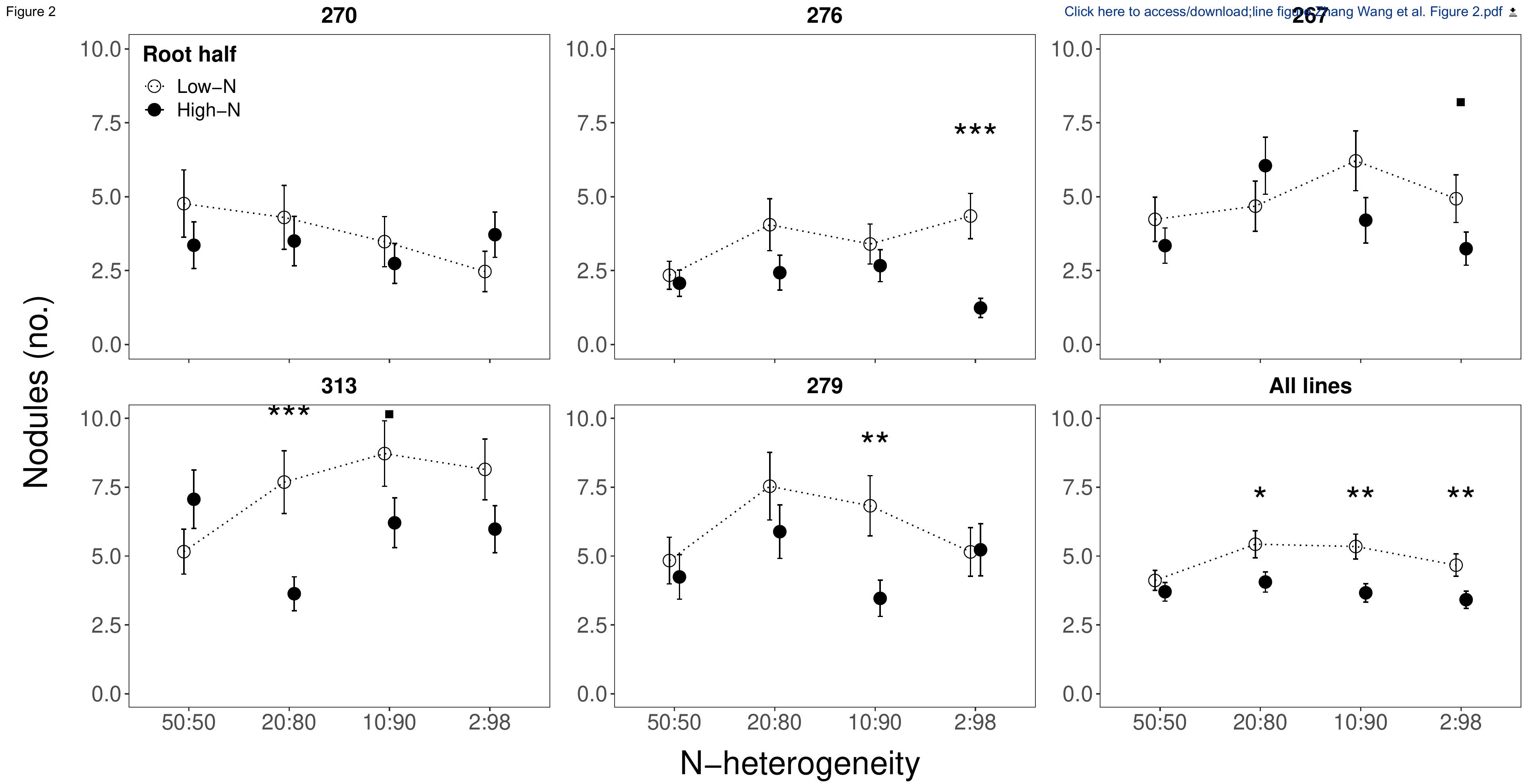






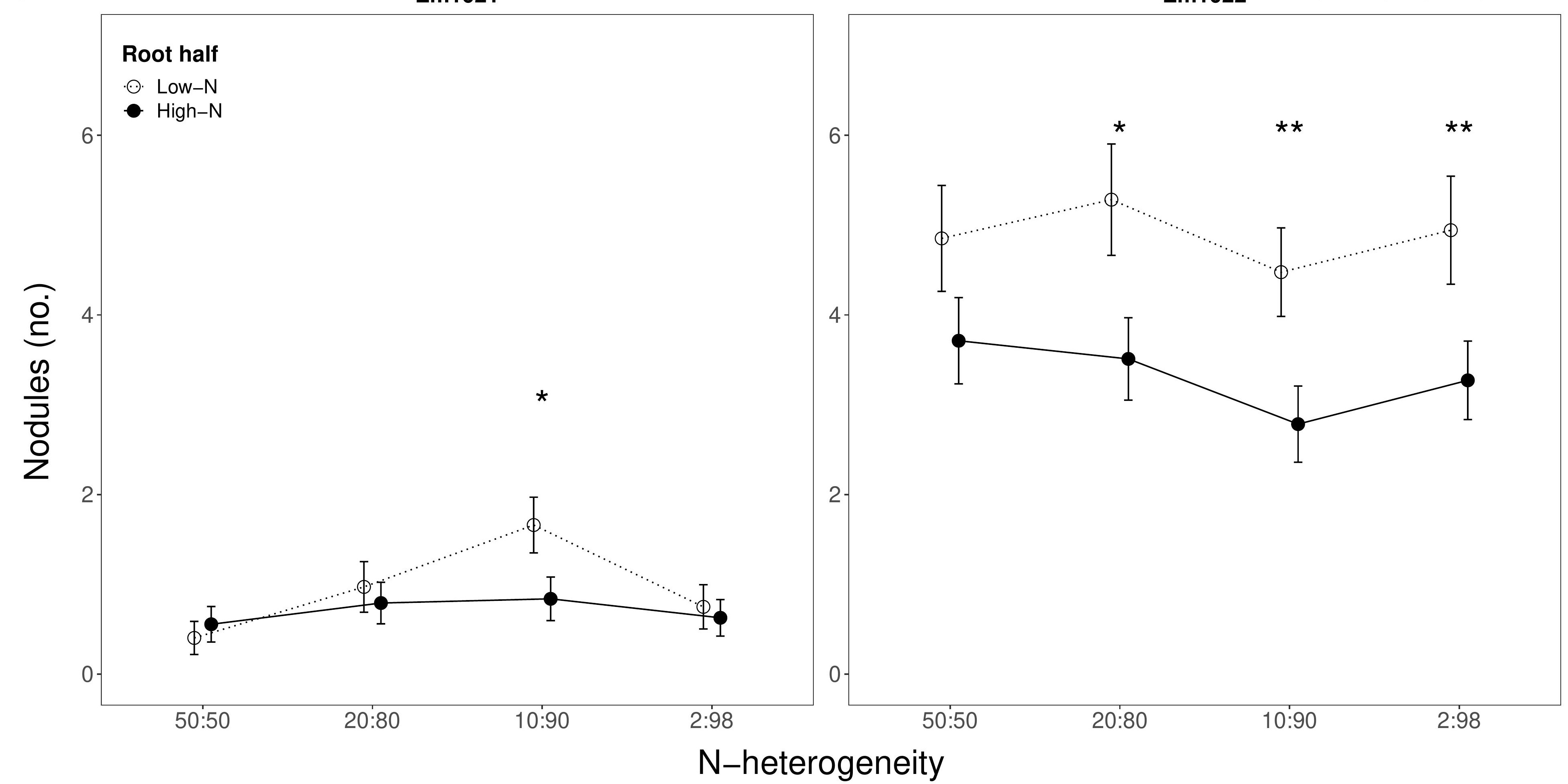



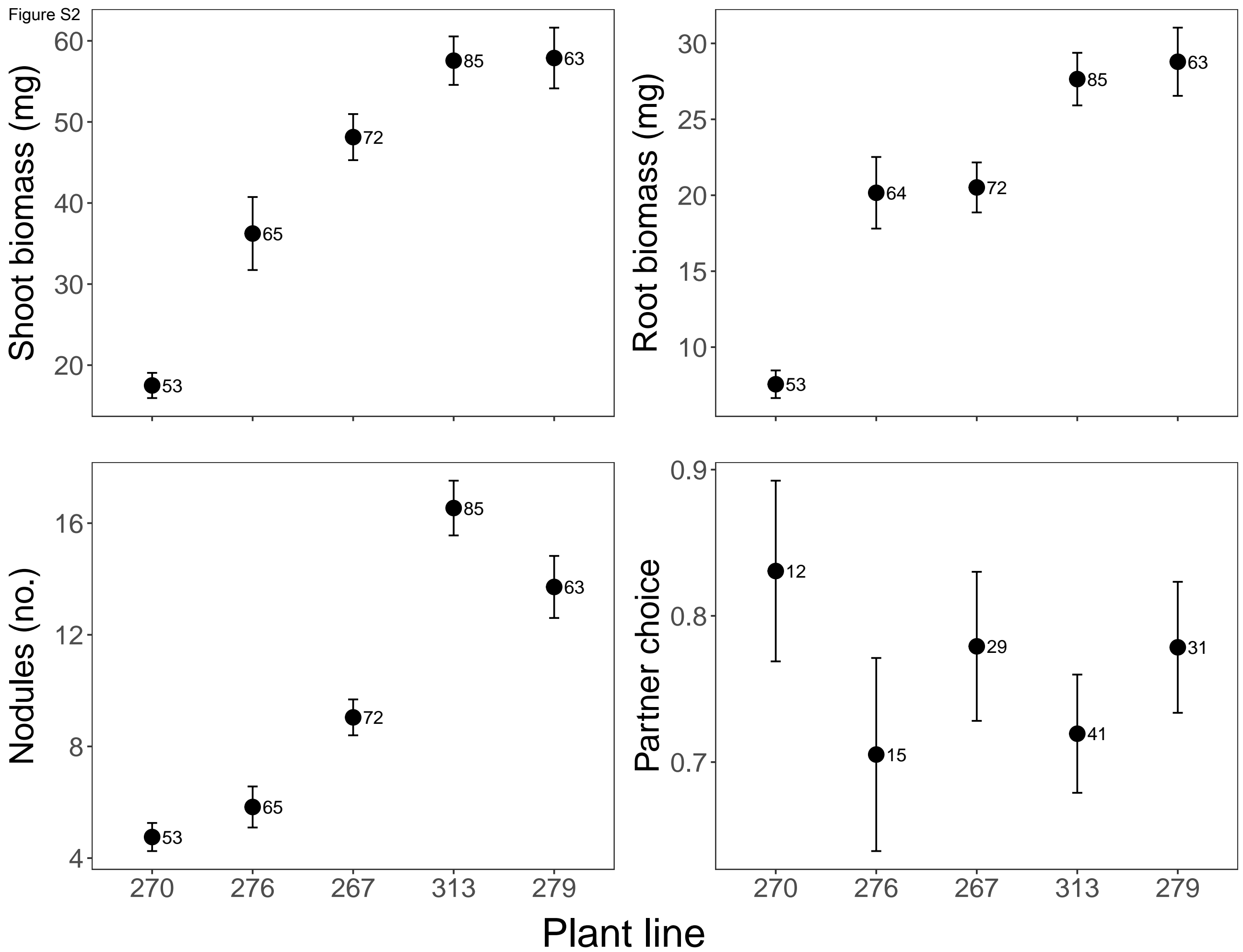

Plant line 


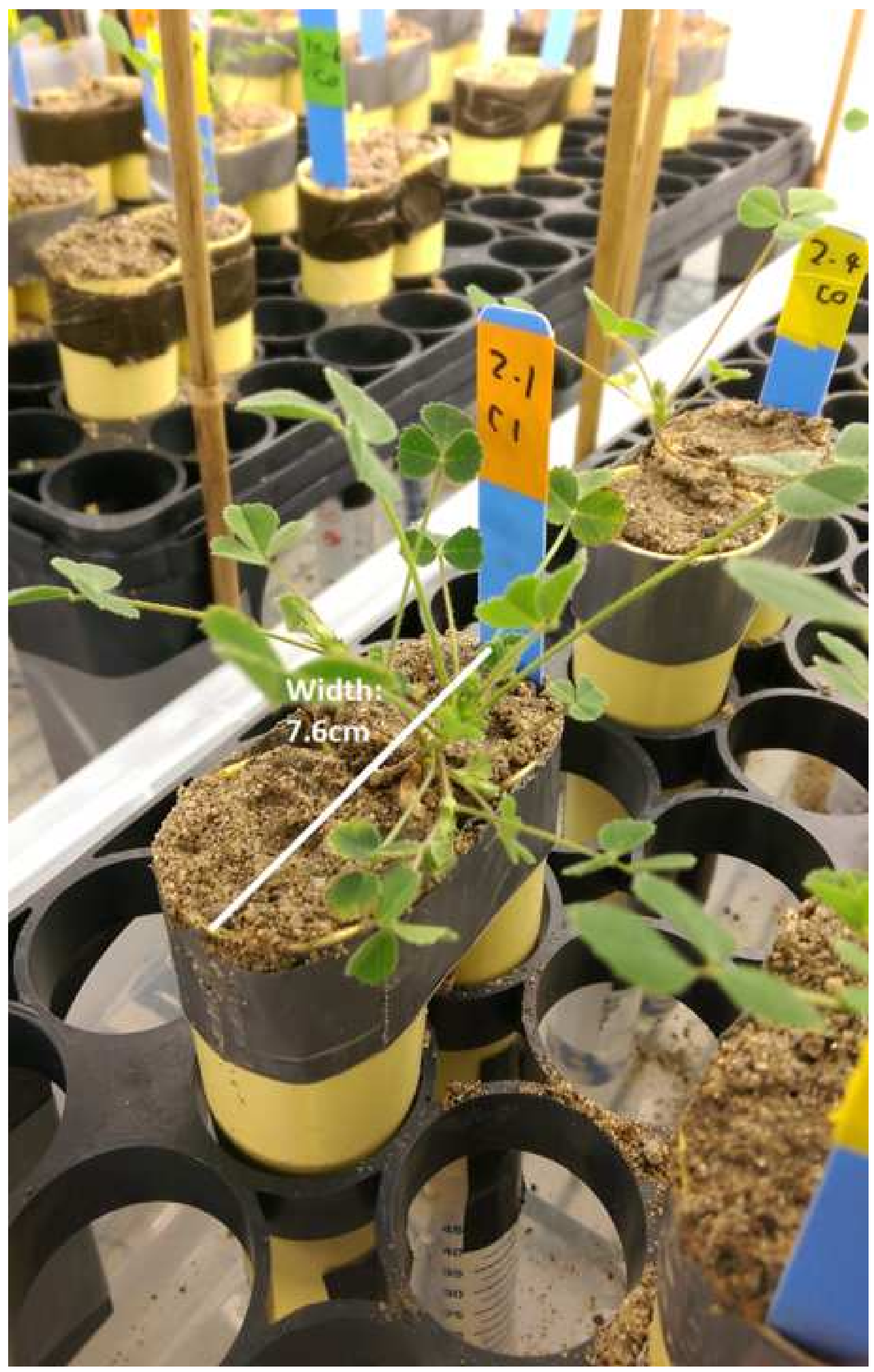




\section{SUPPORTING INFORMATION - Tables}

2 Table S1. Whole-plant models. Accompanies Fig. S1. 3

\begin{tabular}{l|ccc|ccc}
\multicolumn{3}{c}{ Shoot biomass $(\mathrm{g})^{1}$} & \multicolumn{3}{c}{ Root biomass $(\mathrm{g})^{2}$} \\
\hline & $\chi^{2}$ & df & P-value & $\chi^{2}$ & df & P-value \\
\hline (Intercept) & $\mathbf{3 4 4 . 3 4 2}$ & $\mathbf{1}$ & $<\mathbf{0 . 0 0 1}$ & $\mathbf{1 9 6 . 9 3 4}$ & $\mathbf{1}$ & $<\mathbf{0 . 0 0 1}$ \\
treatment & 1.814 & 3 & 0.612 & 1.162 & 3 & 0.762 \\
line & $\mathbf{2 3 9 . 3 0 7}$ & $\mathbf{4}$ & $<\mathbf{0 . 0 0 1}$ & $\mathbf{2 4 3 . 5 3 5}$ & $\mathbf{4}$ & $<\mathbf{0 . 0 0 1}$ \\
treatxline & 4.964 & 12 & 0.959 & 8.612 & 12 & 0.736 \\
\hline \multicolumn{4}{c}{ Total nodules } & $(\text { no. })^{3}$ & \multicolumn{3}{c}{ Partner choice } \\
\hline (Intercept) & $\mathbf{1 7 8 . 3 8 0}$ & $\mathbf{1}$ & $<\mathbf{0 . 0 0 1}$ & $\mathbf{1 0 7 . 7 2 0}$ & $\mathbf{1}$ & $<\mathbf{0 . 0 0 1}$ \\
treatment & 1.161 & 3 & 0.762 & 1.073 & 3 & 0.784 \\
line & $\mathbf{1 9 7 . 5 7 9}$ & $\mathbf{4}$ & $<\mathbf{0 . 0 0 1}$ & 3.035 & 4 & 0.552 \\
treat $\times$ line & 12.912 & 12 & 0.375 & 16.030 & 11 & 0.140 \\
\hline
\end{tabular}

$4 \quad{ }^{1}$ Gamma distribution with square-root link

$5{ }^{2}$ Gamma distribution with square-root link

$6 \quad{ }^{3}$ Poisson distribution with square-root link, observation-level effect included as random effect

$7 \quad{ }^{4}$ Linear mixed model (i.e., Gaussian distribution with identity link) 
8 Table S2. Local half-root level models. Accompanies Figs. 1 and 2.

9

\begin{tabular}{cccc|ccc} 
& \multicolumn{3}{c|}{ Root biomass $(\mathrm{g})^{1}$} & \multicolumn{3}{c}{ Nodules $(\text { no. })^{2}$} \\
\hline & $\chi^{2}$ & df & P-value & $\chi^{2}$ & df & P-value \\
\hline (Intercept) & $\mathbf{1 0 2 . 4 6 7}$ & $\mathbf{1}$ & $<\mathbf{0 . 0 0 1}$ & $\mathbf{8 5 . 6 9 9}$ & $\mathbf{1}$ & $<\mathbf{0 . 0 0 1}$ \\
Covariate & $\mathbf{2 1 1 . 2 6 7}$ & $\mathbf{1}$ & $<\mathbf{0 . 0 0 1}$ & $\mathbf{2 2 1 . 0 6 5}$ & $\mathbf{1}$ & $<\mathbf{0 . 0 0 1}$ \\
line & $\mathbf{4 3 . 8 4 2}$ & $\mathbf{4}$ & $<\mathbf{0 . 0 0 1}$ & $\mathbf{4 8 . 8 1 2}$ & $\mathbf{4}$ & $<\mathbf{0 . 0 0 1}$ \\
treatment & 6.449 & 3 & 0.092 & 2.676 & 3 & 0.444 \\
treatment $\times$ half & $\mathbf{1 0 . 6 9 7}$ & $\mathbf{4}$ & $\mathbf{0 . 0 3 0}$ & 7.253 & 4 & 0.123 \\
covariatextreatment & $\mathbf{8 . 3 5 0}$ & $\mathbf{3}$ & $\mathbf{0 . 0 3 9}$ & 1.236 & 3 & 0.745 \\
linextreatment & 10.512 & 12 & 0.571 & 13.675 & 12 & 0.322 \\
covariatextreatment $\times$ half & 5.537 & 4 & 0.237 & $\mathbf{2 7 . 7 3 1}$ & $\mathbf{4}$ & $<\mathbf{0 . 0 0 1}$ \\
linextreatment $\times$ half & $\mathbf{3 5 . 7 8 9}$ & $\mathbf{1 6}$ & $\mathbf{0 . 0 0 3}$ & $\mathbf{3 2 . 4 4 2}$ & $\mathbf{1 6}$ & $\mathbf{0 . 0 0 9}$ \\
\hline
\end{tabular}

$10 \quad{ }^{1}$ Gamma distribution with square-root link

$11{ }^{2}$ Poisson distribution with square-root link, observation-level effect included as random effect 
12 Table S3. Local half-root level model accounting for strain. Accompanies Figs. 3 and 4. 13

\begin{tabular}{cccc}
\multicolumn{4}{c}{ Nodules (no.) } \\
\hline & $\chi^{2}$ & df & P-value \\
\hline (Intercept) & $\mathbf{3 8 6 . 9 3 6}$ & $\mathbf{1}$ & $<\mathbf{0 . 0 0 1}$ \\
root & $\mathbf{1 3 7 . 2 0 7}$ & $\mathbf{1}$ & $<\mathbf{0 . 0 0 1}$ \\
line & $\mathbf{4 7 . 1 9 3}$ & $\mathbf{4}$ & $<\mathbf{0 . 0 0 1}$ \\
treatment & 4.915 & 3 & 0.178 \\
strain & $\mathbf{1 1 3 . 8 3 8}$ & $\mathbf{1}$ & $<\mathbf{0 . 0 0 1}$ \\
treatment $\times$ half & 0.961 & 4 & 0.916 \\
root $\times$ treatment & $\mathbf{8 . 6 7 1}$ & $\mathbf{3}$ & $\mathbf{0 . 0 3 4}$ \\
line $\times$ treatment & 12.297 & 12 & 0.422 \\
root $\times$ strain & 0.852 & 1 & 0.356 \\
linexstrain & 6.175 & 4 & 0.186 \\
treatment $\times$ strain & 7.243 & 3 & 0.065 \\
root $\times$ treatment $\times$ half & $\mathbf{1 5 . 8 0 9}$ & $\mathbf{4}$ & $\mathbf{0 . 0 0 3}$ \\
line $\times$ treatment $\times$ half & 10.259 & 16 & 0.853 \\
treatment $\times$ half $\times$ strain & $\mathbf{1 0 . 6 1 8}$ & $\mathbf{4}$ & $\mathbf{0 . 0 3 1}$ \\
root $\times$ treatment $\times$ strain & $\mathbf{2 1 . 8 2 4}$ & $\mathbf{3}$ & $<\mathbf{0 . 0 0 1}$ \\
line $\times$ treatment $\times$ strain & $\mathbf{2 5 . 9 1 5}$ & $\mathbf{1 2}$ & $\mathbf{0 . 0 1 1}$ \\
root $\times$ treatment $\times$ half $\times$ strain & $\mathbf{1 0 . 6 6 9}$ & $\mathbf{4}$ & $\mathbf{0 . 0 3 1}$ \\
linextreatment $\times$ half $\times$ strain & 17.765 & 16 & 0.338 \\
\hline
\end{tabular}

$14{ }^{1}$ Poisson distribution with square-root link, observation-level effect included as random effect 
Table S4. Local half-root models re-analyzed from a previous split-root experiment (Batstone et al., 2017). Accompanies Fig. S2.

\begin{tabular}{|c|c|c|c|c|c|c|}
\hline & \multicolumn{3}{|c|}{ Shoot biomass $(\mathrm{g})^{1}$} & \multicolumn{3}{|c|}{ Root biomass $(\mathrm{g})^{1}$} \\
\hline & $\chi^{2}$ & $\mathrm{df}$ & $\mathrm{P}$-value & $\chi^{2}$ & $\mathrm{df}$ & P-value \\
\hline (Intercept) & 166.040 & 1 & $<0.001$ & 266.793 & 1 & $<0.001$ \\
\hline line & 6.452 & 4 & 0.168 & 7.346 & 4 & 0.119 \\
\hline treatment & NA & NA & NA & 18.446 & 1 & $<0.001$ \\
\hline linextreatment & NA & NA & NA & 11.516 & 4 & 0.021 \\
\hline & \multicolumn{3}{|c|}{ Shoot biomass $(\mathrm{g})^{1}$} & \multicolumn{3}{|c|}{ Nodules (no.) $^{2}$} \\
\hline & $\chi^{2}$ & $\mathrm{df}$ & $\mathrm{P}$-value & $\chi^{2}$ & $\mathrm{df}$ & $\mathrm{P}$-value \\
\hline (Intercept) & 1854.000 & 1 & $<0.001$ & 182.990 & 1 & $<0.001$ \\
\hline line & 44.850 & 4 & $<0.001$ & 40.781 & 4 & $<0.001$ \\
\hline treatment & NA & NA & NA & 13.334 & 1 & $<0.001$ \\
\hline linextreatment & NA & NA & NA & 66.958 & 4 & $<0.001$ \\
\hline
\end{tabular}

Top half: Plants $(\mathrm{N}=41$, average $\sim 8$ replicates per line $)$ of the same five lines as used in the present experiment $(270,276,313,267,279)$ grew under rhizobia-free conditions, and split-roots were treated either with $20 \%$ or $80 \% \mathrm{~N}$, the exact same as the $20: 80$ treatment used in the present experiment. Bottom half: Plants $(\mathrm{N}=27$, average $\sim 5$ replicates per line $)$ of the same five lines grew under nitrogen-free conditions, and split-roots were inoculated either with the less or more effective N-fixers Em1021 and Em1022, respectively. For all models, we used generalized mixed model (GLMM) framework in R. Models analyzing shoot biomass as the response included the fixed effect of line and the random effect of tray, while GLMMs for root biomass and nodule number included the fixed effects of line, treatment $(20 \%$ or $80 \%$; Em1021 or Em1022), and their interaction, as well as the random effects of tray and plant. GLMMs were conducted using the lme4 package in R (Bates et al., 2015), and model assumptions were checked

1 by visual inspection of the residuals versus fitted values. ANOVAs were based on type III sums 2 of squares so that term order did not affect results. 
35 Methods S1. Seed sterilization and preparation

36 1. Each seed was scarified by giving it a small cut opposite the embryo with a razor.

37 2. We submerged the seed in $95 \%$ ethanol for 30 seconds, then washed it in bleach for 5 minutes, rinsed it under distilled water for 5 minutes, and finally soaked it in distilled water for 20 minutes.

○ Sterilization following the methods detailed in Gorton et al. (2012)

3. After sterilization, we stored the seeds in the dark at $4{ }^{\circ} \mathrm{C}$ for two days. Afterwards, we removed the seedlings and continued to keep them in the dark for one day at room temperature.

○ Vernalization following the methods detailed in Kassaw and Frugoli (2012)

4. Using Fahräeus agar overlaid with autoclaved filter paper, we placed the seedlings vertically, five per plate, covered with another layer of filter paper. These were left alone for five days.

5. Afterwards, we cut the seedling with an alcohol- and flame-sterilized razor at the junction between the root and the shoot, and transferred the shoot to a new agar plate with autoclaved filter paper. 
Methods S2. Planting

57 Planting occurred six days after exposing the roots, when we transferred plants that had

58 successfully generated equal split roots into a system with a pair of Cone-tainers ${ }^{\mathrm{TM}}$ attached side

59 by side. The Cone-tainers ${ }^{\mathrm{TM}}$ each had an autoclaved polypropylene rope wick (Blueline, Canada)

60 embedded in autoclaved sand (New Canadian Lumber \& Building Supplies, Toronto, ON,

61 Canada) that spanned the length of the Cone-tainers ${ }^{\mathrm{TM}}$ to draw water up. Cotton at the base of the 62 system prevented sand from washing out.

63 1. First, we saturated the sand with water before planting each plant by hand following the 64 methods detailed in Barker et al. (2006).

65 2. We attached falcon tubes with liquid fertilizer of the relevant treatment to the bottom of 66 the each Cone-tainer ${ }^{\mathrm{TM}}$.

67 3. The plants were added to the soil, placing each root half into one of the two Conetainers $^{\mathrm{TM}}$. The roots were then covered with soil.

4. We kept the plants in a tray covered by plastic bags to maintain humidity and reduce contamination, and placed the trays in a growth chamber programmed for a 16-hour photoperiod, a constant temperature of $25^{\circ} \mathrm{C}$, and $70 \%$ humidity.

5. After one week of growth to allow the roots to grow and acclimate, we inoculated every Cone-tainer ${ }^{\mathrm{TM}}$ with a mixed rhizobial culture of Em1021 and Em1022 (more on this below).

6. After two weeks of growth, we removed the plastic bags covering the trays.

7. After three weeks of growth, we replaced all the fertilizer tubes with a new supply.

77 Plants were watered daily, using just enough distilled water to keep the surface of the sand moist. 
78 For plants that were ineffective at absorbing fertilizer from below due to issues with the wick

79 setup, we applied the fertilizer from the surface for both of the root halves, even if only one half

80 had an issue. This was necessary to minimize differences in environmental conditions between

81 root halves. The plants grew for 51 days in total.

\section{Methods S3. Fertilizer}

84 We used four different treatments, corresponding to $50 \%$ and $50 \%$ of the total $\mathrm{N}$ distributed

85 between the half-roots for the control, then $80 \%$ and $20 \%, 90 \%$ and $10 \%$, and $98 \%$ and $2 \%$

86 respectively. The total amount of $\mathrm{N}$ received by each plant was held constant at $3.13 \mathrm{mM} \mathrm{N}$. The

87 macronutrients in the fertilizer were $\mathrm{KNO}_{3}, \mathrm{Ca}\left(\mathrm{NO}_{3}\right)_{2} \cdot \mathrm{H}_{2} \mathrm{O}, \mathrm{CaCl}_{2} \cdot 2 \mathrm{H}_{2} \mathrm{O}, \mathrm{K}_{2} \mathrm{SO}_{4}, \mathrm{~K}_{2} \mathrm{HPO}_{4}$,

$88 \mathrm{MgSO}_{4} \cdot 7 \mathrm{H}_{2} \mathrm{O}, \mathrm{NaCl}$ (exact concentrations given in chart below), and Fe-EDTA (made up

89 according to Barker et al. [2006], Appendix 2.1 for Fahräeus medium). The micronutrients (all

90 with final concentration of $1 \mathrm{ug} / \mathrm{l}$ ) were $\mathrm{MnSO}_{4}, \mathrm{ZnSO}_{4}, \mathrm{CuSO}_{4}, \mathrm{H}_{3} \mathrm{BO}_{3}$, and $\mathrm{NaMoO}_{4}$. Based on

91 table 2 of Moreau et al. (2008), we decreased the concentration of $\mathrm{CaCl}_{2} \cdot 2 \mathrm{H}_{2} \mathrm{O}$ as the

92 concentration of and $\mathrm{Ca}\left(\mathrm{NO}_{3}\right)_{2} \cdot \mathrm{H}_{2} \mathrm{O}$ increased to account for calcium, and we decreased the

93 concentration of and $\mathrm{K}_{2} \mathrm{SO}_{4}$ as the concentration of $\mathrm{KNO}_{3}$ increased to account for potassium.

\begin{tabular}{|c|c|c|c|c|c|c|c|c|}
\hline \multicolumn{2}{|c|}{ N-heterogeneity treatments } & \multicolumn{7}{|c|}{ Macronutrients list (mM) } \\
\hline Proportion N & $\begin{array}{c}\text { Concentration } \mathrm{N} \\
(\mathrm{mM})\end{array}$ & $\mathrm{KNO}_{3}$ & $\begin{array}{c}\mathrm{Ca}\left(\mathrm{NO}_{3}\right)_{2} \\
\bullet\end{array}$ & $\begin{array}{c}\mathrm{CaCl}_{2} \bullet 2 \\
\mathrm{H}_{2} \mathrm{O}\end{array}$ & $\mathrm{K}_{2} \mathrm{SO}_{4}$ & $\mathrm{~K}_{2} \mathrm{HPO}_{4}$ & $\begin{array}{c}\mathrm{MgSO}_{4} \bullet \\
7 \mathrm{H}_{2} \mathrm{O}\end{array}$ & $\mathrm{NaCl}$ \\
\hline $2 \%$ & 0.063 & 0.016 & 0.047 & 4.953 & 1.384 & 2.400 & 2.000 & 0.200 \\
$98 \%$ & 3.0625 & 0.766 & 2.297 & 2.703 & 0.634 & 2.400 & 2.000 & 0.200 \\
\hline $10 \%$ & 0.313 & 0.078 & 0.234 & 4.766 & 1.322 & 2.400 & 2.000 & 0.200 \\
$90 \%$ & 2.8125 & 0.703 & 2.109 & 2.891 & 0.697 & 2.400 & 2.000 & 0.200 \\
\hline $20 \%$ & 0.625 & 0.156 & 0.469 & 4.531 & 1.244 & 2.400 & 2.000 & 0.200 \\
$80 \%$ & 2.5 & 0.625 & 1.875 & 3.125 & 0.775 & 2.400 & 2.000 & 0.200 \\
\hline $50 \%$ & 1.563 & 0.391 & 1.172 & 3.828 & 1.009 & 2.400 & 2.000 & 0.200 \\
\hline
\end{tabular}

95 
Methods S4. Rhizobia inoculation

1. We streaked rhizobia onto tryptone-yeast (TY) media plates and incubated them at $28^{\circ} \mathrm{C}$ for 3 days.

100

2. To create a 2:1 ratio of Em1021:Em1022 strains, we looped bacteria from pure cultures that grew on the plates into a Falcon tube with 50mL of liquid TY media for Em1021, and a Falcon tube with $25 \mathrm{~mL}$ of liquid TY media for Em1022. We stored both tubes along with a blank TY media tube in a shaking incubator at $28^{\circ} \mathrm{C}$ for 3 days.

3. Afterwards, we measured the optical density (OD600) of each strain's culture compared against a blank TY media using a photometer. The average readings across the groups were 0.256 A for 1021 ( \pm SD 0.048), and 0.358 A for 1022 ( \pm SD 0.043).

4. Immediately after obtaining the readings, we mixed the inoculum together in a 2:1 ratio (Em1021:Em1022) and inoculated each root half with $1 \mathrm{~mL}$ of the combined inoculum using a multi-pipettor.

111 Methods S5. Harvesting

112 We separated the shoot from the root halves at the beginning of harvesting, and took note of the 113 following information from each plant:

114 1. The identification information (i.e. plant number, batch number, genotype, treatment)

2. The total number of trifoliate leaves

3. The total number of nodules on each root half

4. The dry weight of the aboveground portion of the plant, and each root half.

118 We dissected viable nodules from each root half, up to a maximum of 5 per root half. We placed 119 the dissected nodules in an Eppendorf tube with dry silica and cotton balls and labelled them. 
120 These nodules were then kept refrigerated at $4{ }^{\circ} \mathrm{C}$. We placed the remaining plant parts

121 separately into individual coin envelopes and dried them at $60^{\circ} \mathrm{C}$ for 2 days before taking dry

122 weight measurements.

123

124 Methods S6. Nodule imbibing and sterilization

125 1. The preserved and dehydrated nodules were transferred from one silica-containing tube to a new $1.5 \mathrm{~mL}$ tube filled with distilled water for rehydration by using featherweight forceps.

2. The imbibed nodules were placed into the fridge for two to eight hours until fully rehydrated prior to subsequent sterilization. The low temperature environment is necessary for imbibing process to prevent nodule degradation.

3. After two to eight hours, we used glass Pasteur pipettes for liquid transferring during sterilization.

4. Nodules were immersed in $95 \%-100 \%$ ethanol (EtOH) for ten seconds, being inverted continually throughout this time so each nodule would be immersed. The EtOH was then discarded using the same pipette.

5. A second pipette was used to add $6 \%$ hypochlorite, inverting the tube for another ten seconds. The hypochlorite was then discarded using the same pipette. the tube with distilled water five times.

140 7. After sterilization, distilled water was added to the tube for subsequent plating. 
141 Note: It was important to use three pipettes during each step of sterilization and also plate

142 nodules right after sterilization because even though most of the hypochlorite was removed, trace

143 amounts can degrade nodules if left for more than a few hours.

144 8. To begin plating, each surface-sterilized nodule was placed on the lid of a sterile petri 145 dish and crushed using alcohol- and flame-sterilized forceps.

1469 9. A sterile cotton swab was used to absorb the contents of the crushed nodule and evenly 147 streak the surface of the agar medium containing a mixture of tryptone, yeast, and salt $148 \quad\left(\mathrm{CaCl}_{2}, 2 \mathrm{H}_{2} \mathrm{O}\right)$.

149 10. All plates were then placed in an incubator set to $29^{\circ} \mathrm{C}$ for the next 72 hours for bacterial 150 replication. 


\section{Supporting Information References}

152 Barker D.G., Pfaff T., Moreau D., Groves E., Ruffel S., Lepetit M., ..., Journet E. P. (2006) $153 \quad$ Medicago truncatula handbook.

154 Bates D., Maechler M., Bolker B., Walker S. (2015) Fitting linear mixed-effects models using 155 lme4. Journal of Statistical Software 67, 1-48.

156 Batstone R.T., Dutton E.M., Wang D., Yang M. \& Frederickson M.E. (2017) The evolution of 157 symbiont preference traits in the model legume Medicago truncatula. New Phytologist $213,1850-1861$.

159 Gorton A.J., Heath K.D., Pilet-Nayel M., Baranger A. \& Stinchcombe J.R. (2012) Mapping the genetic basis of symbiotic variation in legume-rhizobium interactions in Medicago truncatula. G3: Genes, Genomes, Genetics 2, 1291-1303.

Kassaw T. \& Frugoli J.A. (2012) Simple and efficient methods to generate split roots and grafted plants useful for long-distance signaling studies in Medicago truncatula and other small plants. Plant Methods 8. DOI: https://doi.org/10.1186/1746-4811-8-38.

Moreau, D., Voisin A.S., Salon C. \& Munier-Jolain N. (2008) The model symbiotic association between Medicago truncatula cv. Jemalong and Rhizobium meliloti strain 2011 leads to $\mathrm{N}$-stressed plants when symbiotic $\mathrm{N} 2$ fixation is the main $\mathrm{N}$ source for plant growth. 